\title{
Emotion Regulation and Threat Estimation as Mediators of the Relation between Cognitive Functioning and Anxiety in Late Life
}

Caroline M. Ciliberti

West Virginia University

Follow this and additional works at: https://researchrepository.wvu.edu/etd

\section{Recommended Citation}

Ciliberti, Caroline M., "Emotion Regulation and Threat Estimation as Mediators of the Relation between Cognitive Functioning and Anxiety in Late Life" (2013). Graduate Theses, Dissertations, and Problem Reports. 4955.

https://researchrepository.wvu.edu/etd/4955

This Dissertation is protected by copyright and/or related rights. It has been brought to you by the The Research Repository @ WVU with permission from the rights-holder(s). You are free to use this Dissertation in any way that is permitted by the copyright and related rights legislation that applies to your use. For other uses you must obtain permission from the rights-holder(s) directly, unless additional rights are indicated by a Creative Commons license in the record and/ or on the work itself. This Dissertation has been accepted for inclusion in WVU Graduate Theses, Dissertations, and Problem Reports collection by an authorized administrator of The Research Repository @ WVU.

For more information, please contact researchrepository@mail.wvu.edu. 
Emotion Regulation and Threat Estimation as Mediators of the Relation between Cognitive Functioning and Anxiety in Late Life

\title{
Caroline M. Ciliberti
}

\author{
Dissertation submitted to the \\ Eberly College of Arts and Sciences \\ at West Virginia University \\ in partial fulfillment of the requirements \\ for the degree of \\ Doctor of Philosophy \\ in \\ Psychology
}

Barry Edelstein, Ph.D., Chair

Amy Fiske, Ph.D. Michiko Iwasaki, Ph.D. Kevin Larkin, Ph.D.

Aaron Metzger, Ph.D.

Department of Psychology

Morgantown, West Virginia

2013

Keywords: Anxiety; Older Adults; Emotion Regulation

Copyright 2013 Caroline M. Ciliberti 


\begin{abstract}
Emotion Regulation and Threat Estimation as Mediators of the Relation between Cognitive Functioning and Anxiety in Late Life
\end{abstract}

Caroline M. Ciliberti

Background: Rates of anxiety are generally thought to decline in typically aging older adults. Some theorize that this decline is a result of age-related improvements in emotion regulation. Emotion regulation may require the use of complex cognitive processes, however, which can be impacted by cognitive decline. Indeed, the prevalence of anxiety is high among older adults with cognitive impairment. The current study examined emotion regulation and threat perception as possible mediators in the relation between cognitive functioning and anxiety.

Methods: One hundred adults, aged 60 and older, were recruited from nursing homes, assisted living facilities, and the community. All were asked to complete a cognitive screening measure, along with measures of anxiety, emotion regulation, and threat perception. The relation between these variables was examined

Results: Though cognitive impairment predicted anxiety level, neither emotion regulation nor threat perception mediated the relation.

Conclusions: The data suggest that emotion regulation and threat perception may rely on automatic processing, rather than effortful cognitive processing. 


\section{TABLE OF CONTENTS}

TITLE PAGE.



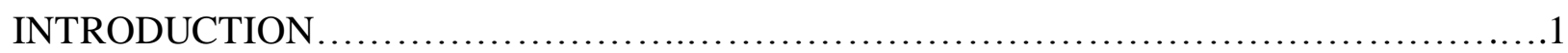



Socioemotional Selectivity Theory and the Positivity Effect.............................2

Emotion Regulation in Late Life....................................................

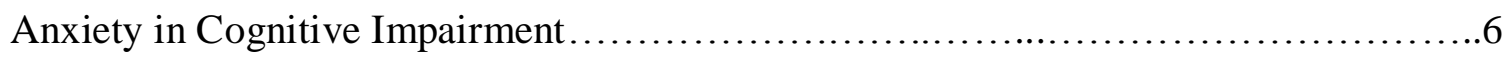

Cognitive Impairment and Emotion Regulation......................................

Cognitive Impairment and the Positivity Effect .......................................

Emotion Regulation, Anxiety, and Threat Estimation................................10

Cognitive Impairment and Threat Estimation......................................11

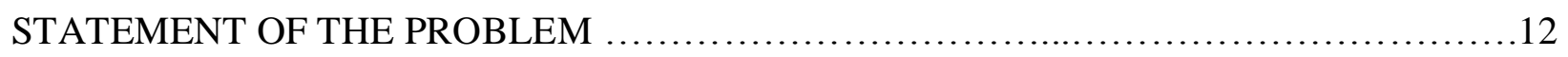

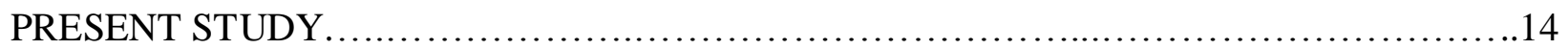



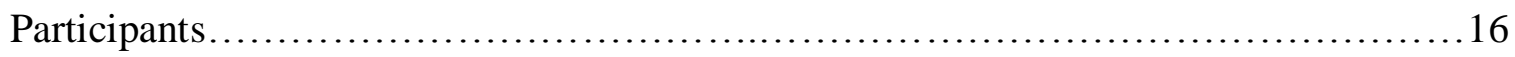

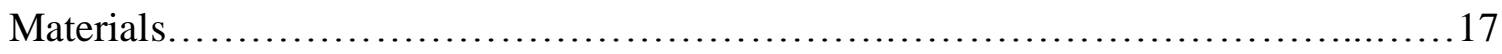

Demographic Questionnaire ............................................17

Montreal Cognitive Assessment ........................................17



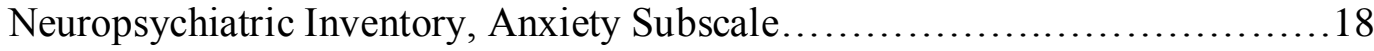

Carstensen Emotion Questionnaire.........................................20

Emotional Film Task ....................................................21




Situational Threat................................................22



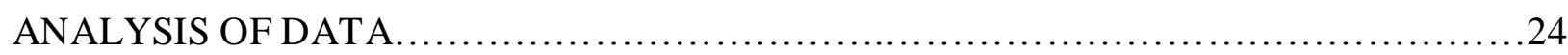



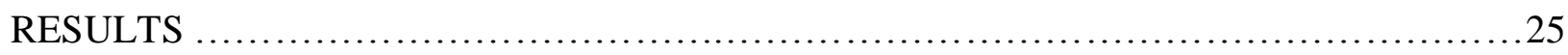

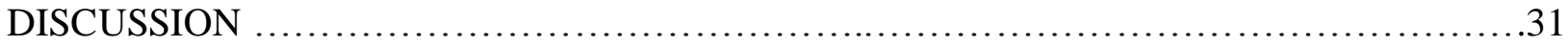

Differences in Anxiety, Emotion Regulation, and Threat Perception According to



Exploratory Analyses Examining Group Differences According to Executive

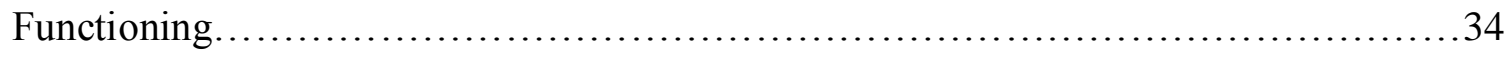

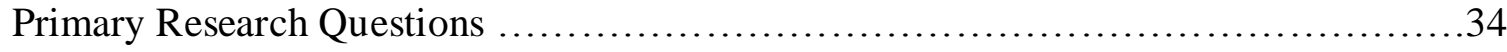

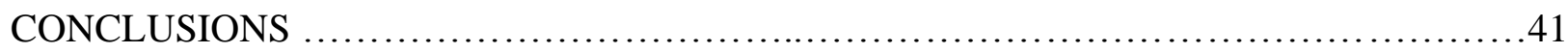

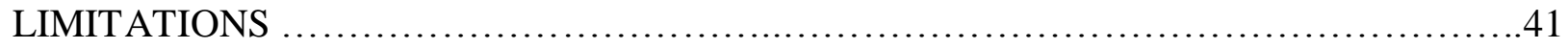

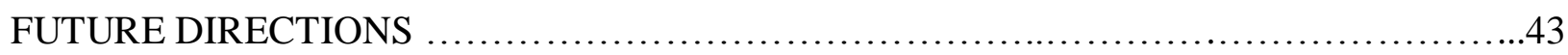



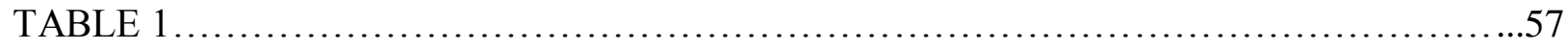



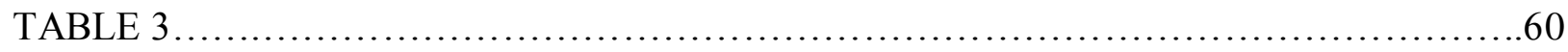

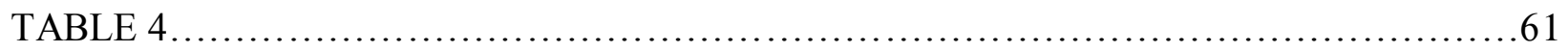

FIGURE CAPTIONS........................................................62

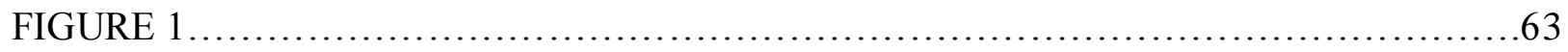

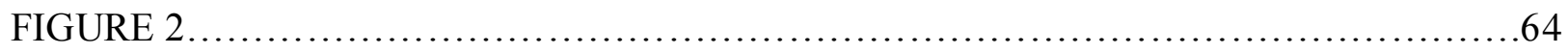

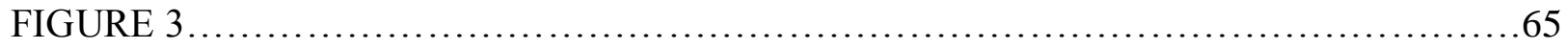




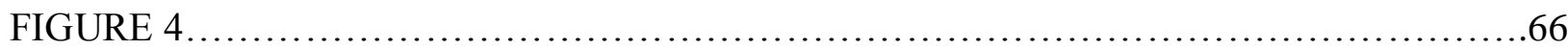

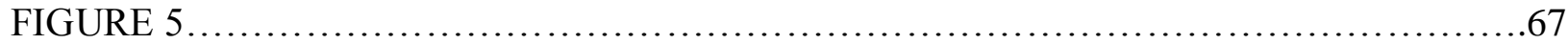

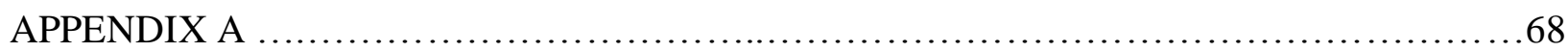

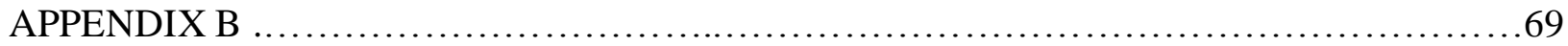

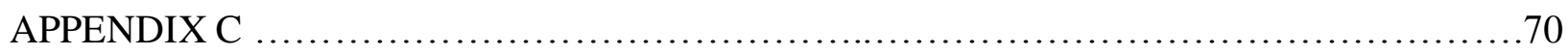

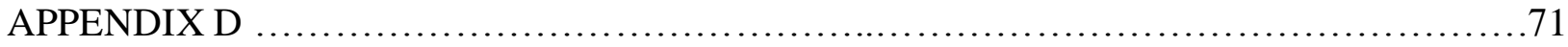



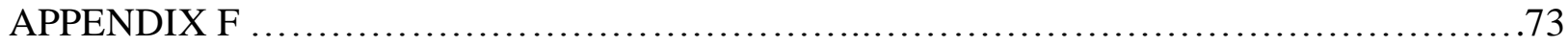


Emotion Regulation and Threat Estimation as Mediators of the Relation between Cognitive Functioning and Anxiety in Late Life

The current study sought to investigate possible causal mechanism of the relation between cognitive functioning and anxiety among older adults. Specifically, it examined factors hypothesized to explain the increased prevalence of anxiety symptoms and disorders among older adults with cognitive impairment compared to typically aging older adults by evaluating emotion regulation and threat perception as possible mediating variables.

To begin, I reviewed literature pertaining to the prevalence of anxiety in late life, followed by a review of the theorized protective impact on emotion regulation on negative affect, and anxiety in particular, in late life. Next, I examined the associations between cognitive functioning and anxiety, emotion regulation, and threat perception. Finally, I proposed and tested a model that attempted to explain the increase in anxiety among people with cognitive impairment as a function of changes in emotion regulation and threat detection.

\section{Anxiety in Late Life}

Anxiety disorders are relatively common in late life; prevalence estimates suggest that between 7.0\% (Gum, King-Kallimanis, \& Kohn, 2009) and 14.2\% (Beekman et al., 1998; Ritchie et al., 2004) of older adults meet criteria for an anxiety disorder. Nonetheless, most researchers have found a lower prevalence of anxiety disorders among older adults, compared to younger adults. A crossectional study of anxiety disorders across the lifespan revealed that the 12-month prevalence of anxiety disorders among people aged 65 and older was nearly one-third that of people aged 18-44 (7.0\% compared to 20.7\%) (Gum et al., 2009). In a review of epidemiological studies of anxiety across the lifespan, Jorm (2000) noted that, though specific 
age cut-offs varied from study to study, most studies found increases in the prevalence of anxiety disorders and anxiety symptoms through mid-life, followed by a drop in late life.

Researchers have attempted to understand the decline in prevalence of anxiety disorders in late life. Some theorize that lower prevalence estimates are an artifact of differences in the presentation of anxiety among older adults (Christensen et al., 1999; Shapiro, Roberts, \& Beck, 1999), underreporting (Tweed, Blazer, \& Ciarlo, 1992), and diagnostic complications caused by frequent physical and psychiatric comorbidities (Brenes et al., 2005; de Buers et al., 1999; Palmer, Jeste, \& Sheikh , 1997). Underreporting and misdiagnosis may not fully account for the declining rates of anxiety disorders, however, and other factors may impact the reduced prevalence (Kryla-Lighthall \& Mather, 2008). Older adults report less frequent negative emotions than younger adults in general (Carstensen, Pasupathi, Mayr, \& Nesselroade, 2000; Jorm, 2000; Kryla-Lighthall \& Mather, 2008), and they less worry and greater perceived emotional control in comparison to younger adults (Gould \& Edelstein, 2010). They also experience less physiological arousal associated with emotional experiences (Lau, Edelstein, \& Larkin, 2001; Levenson, Cartsensen, Friesen, \& Ekman, 1991). Moreover, periods of positive emotional experiences last longer and periods of negative emotional experiences are more fleeting among older adults in comparison to younger adults (Carstensen et al., 2000).

\section{Socioemotional Selectivity Theory and the Positivity Effect}

Researchers explain the declines in negative affect using Socioemotional Selectivity Theory (SST; Carstensen, 2006). Improved emotional regulation in late life may be linked to changes with respect to one's perspective of the future (Carstensen, 2006). SST suggests that, as end of life draws nearer, goals shift from knowledge - acquisition based goals, to goals associated with regulating one's emotional state (Carstensen, 2006). Older adults prioritize emotional wellbeing, 
focusing on deepening relationships and skill, rather than expanding social networks and seeking novelty (Carstensen, 2006), and thus prioritize emotion regulation.

In support of SST, older adults attend to and recall positive emotional stimuli, while younger adults are more likely to attend to and recall negative emotional stimuli (Carstensen \& Mikels, 2005; Isaacowitz, Wadlinger, Goren, \& Wilson, 2006; Mather \& Carstensen, 2005; Murphy \& Isaacowitz, 2008). The finding that older adults favor positive information, both in memory and attention, over negative information is known as the positivity effect (Mather, 2006). Relative to positive and neutral images, older adults are less likely to recall negative images (Turk-Charles, Mather, \& Carstensen, 2003). In fact, neural reactivity to negative, but not positive, stimuli decreases over the course of the lifespan (Kisley, Wood, \& Burrows, 2007). Further, older adults are less likely to respond in negative ways and are less engaged when exposed to unpleasant situations compared to younger adults (Turk-Charles \& Carstensen, 2008). The positivity effect is evident in older adults' recall of autobiographical memories as well. Compared to younger adults, older adults are more likely to distort memory in a positive emotional direction (Mather $\&$ Carstensen, 2005). This suggests that older adults select information that is associated with emotional wellbeing, focusing more on positive information and less on negative information.

\section{Emotion Regulation in Late Life}

Some researchers explain the decreasing prevalence of anxiety and presence of positive biases among older adults by suggesting that older adults are more adept at regulating their emotions and thus, less likely to experience clinically significant levels of anxiety (e.g., KrylaLighthall \& Mather, 2008). Emotion regulation is defined as the process that determines which emotions a person experiences, the extent to which emotions are experienced, and how and when emotions are experienced (Gross, 1998; Gross \& Thompson, 2007). The aim of emotion 
regulation strategies is to reduce negative affect, including anxiety, through mental or behavioral control (Gross, 1998).

Researchers have examined underlying emotion regulation processes (e.g., Gross, 1998, Koole, 2009). In a review of the emotion regulation literature, Gross (1998) discusses five of such strategies: situation selection, situation modification, attentional deployment, cognitive reappraisal, and response modulation. Situation selection is used when a person avoids or approaches certain people, places, or things in order to regulate his or her emotions (Gross, 1998). For example, a person who experiences anxiety when driving on a highway may choose to take secondary routes when traveling. Situation management is a strategy in which a person makes active efforts to change a situation in order to alter its emotional impact. A person who worries about possible injury when riding a bicycle, for instance, may choose to wear a helmet. Attentional deployment is another emotion regulation strategy. It may take the form of distraction (e.g., avoiding unpleasant stimuli), concentration (e.g., focusing on pleasant stimuli), or rumination (e.g., mulling over past negative stimuli). Cognitive change is an emotion regulation technique in which a person modifies the way he or she perceives a situation, and as a consequence, alters his or her emotional response. Finally, response modulation is an emotion regulation technique that involves directly altering physiological (e.g., through medication), behavioral, or experiential responses, after an emotional reaction has taken place. For example, a person may choose to use relaxation strategies to calm his or her anxiety when in a stressful situation. In another review of the emotion regulation literature, Koole (2009) notes that, while there is no empirically validated set of emotion regulation strategies, researchers have identified underlying themes, based on the target of emotion regulation. Identified targets include cognitions associated with emotional salient information, physiological manifestations of 
emotion, and regulation of attention (Koole, 2009). Koole also notes that strategies can be classified according to the function of emotion regulation (2009). Functions include pursuing goals, satisfying hedonic needs, and maintaining the personality system (Koole, 2009).

Perceived control of one's emotions increases with age (Gross, 1998), and the use of such emotion regulation strategies has been shown to predict day-to-day affect levels (Russel et al., 2011). Moreover, there is evidence that older adults use different emotion regulation strategies than younger adults. Specifically, older adults are more likely to use passive emotion regulation strategies (e.g., situation selection, or avoidance) than middle aged adults, who are more proactive (e.g., response modification) about dealing with highly charged emotional situations (Blanchard-Fields, Stein, \& Watson, 2004). Emotion regulation has been studied experimentally using a variety of emotion evocation strategies. In one study, emotional film clips were used to evoke specific emotion experiences, and participants were surveyed about intensity of emotion experienced, as well as their use of emotion regulation strategies (McLaughlin, Mennin, \& Farach, 2007). The study found that participants with an anxiety disorder diagnosis reported using similar emotion regulation strategies but experienced more negative affect in comparison to participants in the control group (McLaughlin et al., 2007). Another study showed that emotional film clips to older and younger adults showed that both groups responded to the emotion induction, but older adults were better able to down-regulate their emotional reaction when instructed (Scheibe \& Blanchard-Fields, 2009).

In addition to differences in emotion regulation strategies, researchers have also examined age related differences in the experience of emotion. Much of the research on emotion in late life shows that older adults report less negative affect and more positive affect than their younger counterparts (see Urry \& Gross, 2010 for a review). Several researchers have explored the 
specific differences in report of emotion and use of emotion regulation strategies between older and younger adults (e.g., Lawton, 2001). Older adults report higher levels of emotion stability, emotion control, and emotional maturity in comparison to younger adults (Lawton, Kleban, Rajagopal, \& Dean, 1992). These differences are moderated by the findings that older adults are less physiologically reactive, less apt to seek out novel sensations, and report more stable levels of positive affect (Lawton et al., 1992).

\section{Anxiety in Cognitive Impairment}

Increased emphasis on emotion regulation resulting from changes in future-time perspective may be a causal factor that explains lower rates of anxiety disorders and anxiety symptoms among older adults. The prevalence of anxiety drops among older adults on the whole; however, the prevalence of anxiety disorders and anxiety symptoms actually increases among a subset of older adults: those with cognitive impairment. Clinically significant anxiety is more common among older adults with dementia than those without dementia (Seignourel, Kunik, Snow, Wilson, \& Stanley, 2008) and those with mild cognitive impairment (MCI; Lyketsos et al., 2002). To a point, more severe cognitive impairment is associated with increases in anxiety symptomatology (Ballard et al., 2000). At the highest levels of impairment, however, anxiety symptoms decline, likely because of lack of recognition and identification of symptoms of anxiety (Bierman, Comjis, Jonker, \& Beekman, 2007). Among people with dementia, the prevalence of anxiety disorders increases, with estimates ranging between five and $21 \%$ (Seignourel et al., 2008). Prevalence estimates of anxiety symptoms are also higher among older adults with dementia, with estimates ranging between $8 \%$ and $75 \%$ (Ballard, Boyle, Bowler, \& Lindesay, 1996; Seignoural et al., 2008). Moreover, the prevalence of anxiety may vary as a function of the type of dementia. Anxiety may be more common among older adults with 
vascular dementia $(\mathrm{VaD})$ than those with dementia, Alzheimer's type $(\mathrm{AD})$, though these findings vary across studies (Ballard et al., 2000; Fuh, Wang, \& Cummings, 2005).

Researchers have examined variables that are associated with anxiety among older adults with cognitive impairment. Social factors, including very high rates of interpersonal interaction, caregiver conflict, physical dependency on others, and stressful life events, are associated with anxiety among older adults with dementia (Orrell \& Bebbington, 1996). Increased disability may also partially account for increases in anxiety among people with cognitive impairment, as anxiety and disability are correlated (Brenes et al., 2008). Among older adults with AD, anxiety is associated with more severe symptoms of $\mathrm{AD}$ and earlier age of onset (Porter et al., 2003). In residential care, higher levels of anxiety are associated with more unmet needs, particularly in the areas of daytime activity, psychological distress, social functioning, memory, and communication (Hancock, Woods, Challis, \& Orrell, 2006). Anxiety symptoms among older adults with dementia and cognitive impairment are associated with a host of negative outcomes, including increases in nighttime awakening (McCurry, Gibbons, Logsdon, \& Teri, 2004) and decreased quality of life (Bannerjee et al., 2006; Hoe, Hancock, Livingston, \& Orrell, 2006). Among people with $\mathrm{AD}$, anxiety symptoms are associated with increases in depression, impairment in activities of daily living, irritability, aggression, mania, tearfulness, behavioral disturbances (e.g., wandering, inappropriate sexual behavior, verbal aggression), and poorer cognitive functioning (Chemerinski, Petracca, Manes, Leiguarda, \& Starkstein, 1998; Ferretti, McCurry, Logsdon, Gibbons, \& Teri, 2001; Teri et al., 1999).

The link between anxiety and cognitive functioning is well established. Several studies have linked late life anxiety to impaired cognitive functioning (see Beaudreau \& O'Hara, 2008 for a review). There appears to be a curvilinear relation between anxiety and cognitive 
functioning among older adults. Mild levels of anxiety may actually improve performance on cognitive tasks, while more severe levels of anxiety are associated with impaired performance (Bierman, Comijis, Jonker, \& Beekman, 2005), and executive functioning is thought to play a particularly important role in stress regulation (Williams, Suchy, \& Roa, 2009). Even among younger adults, the presence of an anxiety disorder is associated with impairment in episodic memory and executive functioning (Airaksinen, Larsson, \& Forsell, 2005). The relation between cognitive impairment and anxiety is complex, and the etiology is unclear. Anxiety may be a precursor to cognitive decline, acting either as a prodromal symptom of cognitive impairment or alternatively, a pathogenic force, taxing the brain (Beaudreau \& O'Hara, 2008). Two longitudinal studies show that baseline anxiety symptoms predict accelerated cognitive decline among older adults (DeLuca et al., 2005; Sinoff \& Werner, 2003), though a third study failed to find such an effect (Wetherell, Reynolds, Gatz, \& Pedersen, 2002).

\section{Cognitive Impairment and Emotion Regulation}

Cognitive impairment is also associated with impaired emotion regulation skills, as emotion regulation strategies require the use of cognitive resources, particularly executive functioning, working memory, and attention (Urry \& Gross, 2010). Poorer emotion regulation skills are associated with poorer ability to differentiate between emotions (Barrett, Gross, Christensen, \& Benvenuto, 2001), a skill that is often impaired among people with dementia and other types of cognitive impairment (e.g., Fernandez-Duque \& Black, 2005). Further, in comparison to typical older adults, older adults with cognitive impairment are worse when instructed to down-regulate emotional response after a startling and aversive stimulus is presented (Goodkind, Gyurak, McCarthy, Miller, \& Levenson, 2010). In an experimental manipulation of emotion regulation when exposed to positive stimuli, older adults with dementia 
performed similarly to older adults without dementia (Henry, Rendell, Scicluna, Jackson, \& Phillips, 2009). This study, however, did not examine ability to regulate negative affect, a key component in the development of anxiety. In another example examining the link between cognitive processes and emotion regulation strategies (i.e., attentional deployment), a study of attentional biases towards threat showed that younger adults with high levels of trait anxiety, as measured by the State-Trait Anxiety Inventory (STAI, Spielberger, 1983), attended to threatening stimuli more than those with low levels of trait anxiety (Derryberry \& Reed, 2002). This effect, however, was moderated by attentional control. Trait-anxious adults with high levels of attentional control were better able to shift attention away from threatening stimuli in comparison to those with lower attentional control (Derryberry \& Reed, 2002).

The interaction between cognitive functioning and emotion regulation may have implications for anxiety among older adults with cognitive impairment. Though much of the emotion regulation literature discussed above suggests that older adults are more adept at regulating their emotions than younger adults, most studies examined older adults without cognitive impairment. Emotion regulation often requires the use of complex cognitive processes, which may be impacted by cognitive decline. In contrast to typically aging older adults, research suggests that older adults with cognitive impairment may not have enhanced emotion regulation skills, and in fact, may have impaired emotion regulation skills (e.g., Goodkind et al., 2010; Urry \& Gross, 2010).

\section{Cognitive Impairment and the Positivity Effect}

As discussed above, typically developing older adults (i.e., those without cognitive impairment) display evidence of a positivity effect, attending to positive stimuli and avoiding negative stimuli. This effect, however, appears to be reversed when cognitive resources are 
taxed (Knight et al., 2007). Under a divided attention condition, when cognitive resources are strained, non-impaired older adults attend to negative stimuli more than younger adults (Knight et al., 2007). Knight and colleagues argue that the positivity effect observed in older adults results from activation of emotion regulation goals and cognitive resources needed to attain such goals. Therefore, in cognitively impaired older adults, where cognitive resources are likely to be strained, older adults may be more likely to attend to negative than positive stimuli.

Other research suggests that limitations and strains on cognitive resources also appear to affect older adults' ability to retain emotional stimuli in memory; older adults with AD do not evidence enhanced memory for emotional stimuli (Hamann, Monarch, \& Goldstein, 2000). Mather and Knight (2005) examined executive functioning and its effects on positivity effects. They found that older adults, on the whole, were more likely to retain positive stimuli in memory than negative stimuli in comparison to younger adults. These differences, however, were mediated by executive functioning. Older adults who performed best on measures of executive functioning were more likely to display evidence of the positivity effect, while those who performed poorly on measures of executive functioning were biased towards negatively valenced stimuli (Mather \& Knight, 2005). These findings suggest that older adults with cognitive impairment may have poorer emotion regulation skills than their peers.

\section{Emotion Regulation, Anxiety, and Threat Estimation}

Emotion regulation may also play an important role in detection of and attention to threatening stimuli, as anxiety is associated with misinterpretation of situations involving potential threat and overestimation of the probability of harm from threatening stimuli (Shapiro, Roberts, \& Beck, 1999). In general, older adults are thought to be equally adept as younger adults at identifying threatening faces and situations, in spite of biases towards positive 
emotional stimuli (Mather \& Knight, 2006; Ruffman, Ng, \& Jenkin, 2009). Anxiety has been shown to impact threat detection in both young adults (see Mobini \& Grant, 2007 for a review) and older adults. When anxious mood was induced in a sample of older adults, biases towards mood-congruent threatening stimuli emerged (Fox \& Knight, 2005). In other words, older adults were more likely to attend to threatening stimuli than non-threatening stimuli when anxious mood was induced in comparison to neutral mood (Fox \& Knight, 2005). Implicit attitudes may also play a role is of in perception of anxiety inducing or threatening stimuli. It is possible that cognitive impairment (particularly deficits in executive functioning and attention) emotional dysregulation may explain this occurrence, if attentional deployment towards non-threatening stimuli protects against anxiety. Jasper and Witthoft (2012) used the Affective Misattribution Procedure (AMP; Payne, Cheng, Govorun, \& Stewart, 2005) to examine the effect of priming with health-threatening images on subsequent evaluations of neutral visual stimuli in a sample of younger adults with health anxiety. They found that participants with high levels of health anxiety were less likely to describe neutral images as "pleasant" when primed with health threatening images, compared to trials when they were primed with neutral or pleasant images (Jasper \& Witthoft, 2012).

\section{Cognitive Impairment and Threat Estimation}

In addition to the presence of anxiety, cognitive impairment may affect the ability to accurately identify, assess, and attend to threat, thus resulting in increased anxiety. Though research has shown that older adults with early dementia maintain their ability to accurately identify threatening faces, they are more likely to over-estimate situational threat level (Henry et al., 2009). In a study of threat detection, researchers showed photographs of high and low-threat situations, and high and low threat faces to participants with mild cognitive impairment (MCI) 
and dementia, and to participants who were typically aging older adults. Participants were then asked to rate the photographs on a scale from one to seven according to how threatening each one was. The groups were all able to successfully distinguish high from low threat faces. On the situation task, the dementia group was not able to distinguish high from low threat situations, overestimating threat in low threat situations (Henry et al., 2009). Considering the changes in emotion regulation skills discussed above, it is possible that worse emotion regulation skills could also be associated with changes in threat estimation. For example, people who are less skilled at avoiding threatening stimuli and restructuring fearful thoughts may be more apt to misinterpret or overestimate threat associated with a stimulus.

\section{Statement of the Problem}

Most studies that report declines in the prevalence estimates of anxiety in late life draw from community samples and exclude older adults with cognitive impairment (e.g., Beekman et al., 1998). Those that assess the prevalence of anxiety among older adults with cognitive impairments find increases in anxiety disorders and anxiety symptoms (e.g., Seignourel, Kunik, Snow, Wilson, \& Stanley, 2008). With poor understanding of the causal mechanism behind the increases of anxiety among older adults with cognitive impairment, there is little research on effective interventional strategies.

Several researchers have attempted to explain the drop in prevalence of anxiety disorders and anxiety symptoms among typically developing older adults, by suggesting that older adults are more adept than younger adults at coping with stressors because of improved emotion regulation skills (e.g., Carstensen, 2006; Gross, 1998), but beyond examining risk factors (e.g., Orrell \& Bebbington, 1996), none have attempted to identify potential mechanisms of action that explain the increases of anxiety observed in older adults with cognitive impairment. 
It is possible that cognitive decline impacts emotion regulation skills, thereby cancelling their beneficial impact associated with aging. Because emotion regulation skills are thought to protect against anxiety in late life (e.g., Carstensen, 2006), and older adults with cognitive impairment are less adept at using such strategies (e.g., Goodkind et al., 2010), older adults with cognitive impairment may be less able to regulate problematic anxiety.

Moreover, older adults with cognitive impairment are able to identify facial and situational threat, but they tend to overestimate threat associated with such stimuli, possibly making them more susceptible to anxiety-arousing stimuli (Henry et al., 2009). In other words, older adults with cognitive impairment are less adept at coping with anxiety, and they are more likely to view the world as a threatening place.

Taken together, these factors may help to explain the increase in prevalence of anxiety disorders and anxiety symptoms among older adults with cognitive impairment, in comparison to those who are typically aging. Specifically, older adults with dementia may be less effective in the use of emotion regulation strategies (including SST) because of cognitive decline. This could result in a shift from a positivity bias, as observed in typically aging older adults, to a negativity bias. Poorer emotion regulation skills, combined with poorer ability to distinguish threatening stimuli from non-threatening stimuli may make older adults with dementia especially vulnerable to developing problematic anxiety.

Should this hypothesized relation exist, it could have implications for the treatment of anxiety in older adults with cognitive impairment. Several interventional studies developed for other populations (e.g., borderline personality disorder, Gratz \& Gunderson, 2006; adjustment following a cancer diagnosis, (Cameron, Booth, Schlatterer, Ziginskas, \& Harman, 2006), targeting emotion regulation skills have been shown to be effective in alleviating psychological 
distress. It is possible that similar emotion regulation coaching or augmentation approaches could be adapted to provide relief to older adults with cognitive impairment who experience significant anxiety.

\section{Present Study}

The proposed study examined the extent to which level of anxiety among older people with dementia could be explained by a loss of protective skills (ER strategies) and change in perception of anxiety triggers (threat detection) as a result of diminished cognitive functioning. A model for the hypothesized relation is shown in Figure 3. It is hypothesized that there is a relation between anxiety levels and cognitive functioning such that diminished cognitive abilities are associated with increased levels of anxiety. I hypothesized that the relation between anxiety and cognitive functioning is mediated by changes in emotion regulation strategies and threat processing. The following specific relations were examined via model pathways:

1. To examine the impact of emotion regulation strategies on the relation between cognitive functioning and anxiety, I tested two hypotheses.:

a. Previous studies have shown that older adults with dementia are worse at down-regulating emotions (Goodkind et al., 2010) and less likely to evidence the positivity effect observed in typically aging older adults (e.g., Hamann et al., 2000; Mather \& Knight, 2005). Considering these findings, and the findings that emotion regulation strategies are cognitively taxing (Urry \& Gross, 2010), I hypothesized that older adults with poorer cognitive functioning would be less adept at using emotion regulation skills.

b. Because emotion regulation is theorized to explain the lower prevalence of anxiety symptoms and disorders among typically developing older adults 
(e.g., Carstensen, 2006), I hypothesized that older adults with poorer emotion regulation strategies would have higher levels of anxiety.

c. Thus, I hypothesized that the relation between cognitive functioning and anxiety would be explained, in part, by changes in emotion regulation.

2. To examine the relation between emotion regulation, and threat estimation, the following hypothesis was examined.:

a. It was hypothesized that emotion regulation would be associated with threat estimation, as emotion regulation skills may be essential to avoid threatening stimuli and mitigate their impact (Gross, 1998).

3. To examine the meditational role of threat perception on the relation between cognitive impairment and anxiety, the following hypotheses were examined.:

a. Based on the findings of Henry and colleagues (2009), it was hypothesized that increases in cognitive impairment would be associated with overestimation of threat.

b. The research indicates that older adults are more likely to attend to mood congruent stimuli, and overestimation of threat is associated with increases in anxiety (e.g., Derryberry \& Reed, 2002; Mobini \& Grant, 2007).

Consequently, I hypothesized that overestimation of threat would be associated with increases in anxiety.

c. I hypothesized that Threat Perception would mediate the relation between cognitive functioning and anxiety, as older adults with cognitive impairment are more likely to overestimate situational threat, when compared to older 
adults without cognitive impairment (Henry et al., 2009), and higher levels of perceived threat could be casually associated with increases in anxiety.

\section{Method}

\section{Participants}

One hundred adults, age 60 and older, were recruited. According to Mueller and Hancock (2010), a minimum of five participants per parameter measured are required for the proposed analysis (structural equation modeling) to be adequately powered. One hundred participants goes beyond the suggested minimum number of participants, but is more in line with the precedent of obtaining larger sample sizes when using structural equation modeling (Hancock \& Mueller, 2010). Participants who scored lower than 10 on a screening measure of cognitive functioning (the Montreal Cognitive Assessment, or MoCA; Nasreddine et al., 2005) were excluded. Participants with scores below 10/30 on the MoCA were excluded because the curvilinear relation between anxiety and cognitive functioning could impact results (Bierman, Comijis, Jonker, \& Beekman, 2005). For participants with profound impairment (MoCA scores less than 10), reliability of self-report data is questionable, and previous studies have excluded such participants (e.g., Bodice et al., 2008). Those who were non-verbal were excluded from the study. Because the AMP utilizes Chinese characters as neutral stimuli, participants who spoke or read Chinese were excluded to avoid confounding the results. To ensure a range in level of cognitive functioning, participants were recruited via community advertisements, from senior centers, from assisted living centers, and from nursing facilities in the Pittsburgh, PA; Morgantown, WV; and Buffalo, NY areas. Consent was obtained from all participants capable of providing consent. For those with a health care surrogate, consent to participate was obtained from the participant's appointed decision maker, and assent was obtained from the participant. A 
proxy (e.g., caregiver, spouse, friend, or close family member) was identified for participants, and consent was obtained. All tests were administered by the writer, or an undergraduate research assistant who had received training on the measures.

\section{Materials}

Demographic questionnaire. Participants completed a demographic questionnaire. Information regarding race, marital status, years of education, current living situation, and relationship of proxy was assessed to characterize the sample. Participants were also asked to report chronic health conditions. See Appendix A.

Montreal Cognitive Assessment (MoCA; Nasreddine et al., 2005). The MoCA is a brief, 30 point, cognitive test used to screen for symptoms of cognitive impairment. Items assess short term recall, delayed recall, visuospatial ability, executive functioning, attention, concentration, working memory, language, and orientation. Performance of the MoCA has been examined in older adults with MCI, AD, and healthy controls (Nasreddine et al., 2005). According to Nasreddine and colleagues (2005), the MoCA has good internal consistency when tested in a sample of participants with MCI, Alzheimer's Disease, and healthy controls $(\alpha=$ 0.83). MoCA scores are also strongly correlated with Mini Mental Status Exam scores, and the MoCA is both sensitive and specific for identifying cognitive impairment in older adults (Nasreddine et al., 2005). The MoCA is more sensitive in identifying mild cognitive impairment (detecting $83 \%$ of the positive cases) and dementia (detecting $94 \%$ of the positive cases) than the Mini Mental State Exam (MMSE; Folstein, Folstein, \& McHugh, 1975), which only detected 17 $\%$ of the cases with MCI and $25 \%$ of those with dementia in a study by Smith, Gildeh, and Holmes (2007). Reports of specificity vary, with estimates ranging from 50\% (Smith et al., 2007) to $87 \%$ (Nasreddine et al., 2005). The MoCA also has been validated in many different 
populations with changes in cognitive functioning, including Parkinson's disease (Gill, Freshman, Blender, \& Revina, 2008), and brain metastases (Olson, Chhanabhai, \& McKensie, 2008). To examine the MoCA items, see Appendix B.

Anxiety: The latent variable, "Anxiety," was modeled using two continuous indicator variables: a self-report measure of anxiety (the Geriatric Anxiety Inventory) and a measure of proxy-reported anxiety (the Neuropsychiatric Inventory, Anxiety subscale).

Geriatric Anxiety Inventory (GAI; Pachana et al., 2007). The GAI is a 20 item yes/no format self-report measure of anxiety developed specifically for use with older adults. Scores are summed, such that higher scores suggest higher levels of anxiety. In a sample of community dwelling older adults, it was shown to have good internal consistency, with a Cronbach's alpha of .91. According to Pachana and colleagues (2007), the GAI also demonstrates concurrent validity, as GAI scores are highly correlated with other measures of anxiety, including the STAI (Spielberger, 1983), Beck Anxiety Inventory (BAI; Beck et al., 1988), and Penn State Worry Questionnaire (PSWQ; Meyer et al., 1990). Moreover, it shows good discriminant validity among people with cognitive impairment (Boddice, Pachana, \& Byrne, 2008). For a list of the GAI items, see Appendix C.

Neuropsychiatric Inventory, Anxiety Subscale (NPI; Cummings, 1997). The NPI is a structured interview designed to assess the frequency and severity of symptoms of psychopathology among older adults with dementia. The interview is designed to be administered to a caregiver, and is validated for use with dementia ranging from mild to severe. The measure assesses disturbances in 12 areas: hallucinations, delusions, agitation, anxiety, dysphoria, euphoria, apathy, irritability, disinhibition, nighttime 
disturbances, aberrant motor behavior, and appetite and eating disturbances. For the purpose of this study, only the anxiety subscale was administered. A screening question is administered first. Those who deny observing signs of anxiety in the screening item receive a score of zero. Those who positively endorse the screening question are asked follow up questions that assess the presence of specific symptoms of anxiety, then the frequency and severity of those symptoms. The total score is determined by multiplying a measure of the frequency of symptoms ( $1=$ occasionally- less than once per week; $2=$ often- about once per week; $3=$ frequently- several times per week but less than every day; $4=$ very frequently- once or more per day $)$ by the severity of the symptoms $(1=$ mildanxiety is distressing but usually responds to redirection or reassurance; $2=$ moderateanxiety is distressing, anxiety symptoms are spontaneously voiced by the patient and difficult to alleviate; $3=$ marked- anxiety is very distressing and a major source of suffering for the patient). Convergent validity was determined by examining the equivalent subscales of the NPI to the BEHAVE - AD and the Hamilton Rating Scale for Depression (Cummings, 1997). All correlations were significant at the $p<.05$ level, though the correlation coefficients were not reported. The NPI also evidenced betweenrater reliability, with $93.6 \%$ and $100 \%$ concordance between independent raters across the 12 subareas. When a second NPI was re-administered after a three week period of time, test - retest reliability $(r=.79$ for the frequency of symptoms and $r=.86$ for the severity) was very good (Cummings, 1997). Moreover, scores on several subscales, including the anxiety subscale, are sensitive to change with treatment (Cummings, 1997). For participants residing in a nursing home setting, the Neuropsychiatric InventoryNursing Home Version (NPI-NH; Wood et al., 2001) was administered. The NPI-NH 
utilizes the same questions, but the caregiver distress item (which is not factored into total NPI score) reflects occupational disruption. The NPI anxiety subscale questions are listed in Appendix D.

Emotion Regulation: Emotion regulation was modeled as a latent variable. In a multimethod approach to capture the construct of emotion regulation, a self-report measure of emotion regulation (the Carstensen Emotion Questionnaire), an emotion regulation behavioral task (Emotional Film Clip), and a task that shows evidence of emotion regulation in the form of positivity bias (the Affective Misattribution Procedure) were used.

Carstensen Emotion Questionnaire (CEQ; Carstensen, 2000). The CEQ assesses the frequency with which the participant experiences happiness, sadness, fear, and disgust on a scale ranging from 1 (never) to 4 (often). The CEQ also assesses control of emotions, assessing the participants' perceived ability to control both the internal experience of such emotions and their external expression on a Likert-type scale with scores ranging from 0 (indicating 'not at all') to 4 (indicating very well). This measure has been used with older adults (Gould \& Edelstein, 2010, Gross et al., 1997; Kennedy, Mather, \& Carstensen, 2004). Gould and Edelstein calculated two subscales by totaling responses from the CEQ : inner control and external control. Cronbach's alphas suggest good internal consistency for both the inner $(\alpha=.81)$ and external control $(\alpha=.83)$ subscales among community dwelling older adults (Gould \& Edelstein, 2010). Higher levels of emotion control on the CEQ score also were associated with lower levels of negative affect (i.e., worry and sadness) in a sample of community-dwelling older adults (Gould \& Edelstein, 2010). For the purposes of the current study, total CEQ score was 
calculated by totaling scores from the internal and external control subscales. See Appendix E.

Emotional film task. Film clips have been successfully used to evoke emotion in many studies (e.g., Gross \& Levensen, 1995; Sheibe \& Blanchard-Fields, 2009). Two film clips, both shown used in previous emotion evocation studies (Gross \& Levensen, 1995), were shown to participants. The first clip, depicting color changing bars, was intended to evoke a neutral reaction. The second clip, depicting a chase scene from a movie, was intended to evoke a fear or anxiety reaction (see Gross \& Levensen, 1995). After watching each clip, participants were asked to complete a post-film questionnaire, where they ranked the intensity of emotions experienced while watching the film on a scale from 0 (none) to 8 (extremely), and rank how pleasant or unpleasant watching the film was. This procedure is modeled after the procedure used by Gross and Levensen (1995), and outlined by Rottenberg, Ray, and Gross (2007). For the purpose of this study, maximum emotion evoked by the emotional film (using the 0-8 rating scale) was used in analyses. To see the post-film questionnaire, see Appendix F.

Affective Misattribution Procedure (AMP; Payne, Cheng, Govorun, \& Stewart, 2005). AMP is a computerized program used to examine the impact of affective priming on implicit attitudes, and it has been used to measure positivity/ negativity effect (e.g., Payne et al., 2005). The presence of the positivity effect can be considered an indicator of effective emotion regulation. The current study used the AMP to examine the impact of emotionally valenced stimuli on perception of how favorable a neutral stimulus, according to the procedure used by Payne and colleagues. As in the Payne et al. study (2005), participants were shown an emotionally valenced image, followed by a neutral 
image. Participants were then asked whether the neutral image was pleasant or unpleasant in appearance. In a college-aged sample, the AMP has been used to test priming effects on favorable and unfavorable evaluations of people and situations and racial attitudes, and it has been shown to be correlated with intended behavior and explicit self-report (Payne et al., 2005). In the current study, the participants were told that a photograph would appear on the screen, followed by a character. Either a positively or negatively valenced photograph was shown from the International Affective Picture System (IAPS; Lang, Bradley, \& Cuthbert, 1997), followed by a neutral stimulus (i.e., a Chinese character). The participants were asked to ignore the photograph and rate whether the character is generally pleasant, generally unpleasant, or neutral. The percent of primed positive endorsed as "pleasant", an indicator of positivity biases, is reported in the current study. For an example of this sequence, taken from Payne et al., see Figure 1. The IAPS is a set of color photographs that were developed to evoke a variety of emotions. The photographs have been used in a variety of studies, with a variety of ages, and norms are available detailing the type and strength of emotion experienced when viewing each photograph (Bradley \& Lang, 2007). Norms are available for older adults (Gruhn \& Scheibe, 2008).

Threat Perception: The latent variable, "Threat Perception," was modeled using a measure of situational threat estimation and a measure of facial threat estimation.

Situational Threat Estimation Task. Using the procedure described by Henry et al. (2009), participants were asked to rate the threat level associated with 20 (10 threatening and 10 non-threatening) photographs of situations taken from the IAPS (Lang et al., 2005). As in the Henry et al. study, participants were asked to rate the threat 
associated with each photograph on a scale from -3 (not at all dangerous) to 3 (very dangerous). Average threat rating was reported in the current study. For an example of a similar task used in Ruffman and colleagues' (2006) study, see Figure 2.

Facial Threat Detection Task. Also using the procedure described by Henry et al. (2009), participants were asked to rate the threat level associated with 20 (10 threatening and 10 non-threatening) color photographs of humans from the International Affective Picture System (IAPS; Lang, Bradley, \& Cuthbert, 2005). Similarly to the situational threat detection task and as in the Henry et al. (2009) study, participants were asked to rate the threat associated with each facial photograph on a scale from -3 (not at all dangerous) to 3 (very dangerous). As in the Situational Threat task, average threat rating was used in the current study. Again, see Figure 2 for an example of a similar task used by Ruffman and colleagues (2006).

\section{Procedure}

Consent was obtained from all participants. Participants were asked to complete a battery of measures, including 3 tasks (AMP, emotional film task, and threat rating task), three questionnaires (two anxiety rating scales and an emotion regulation rating scale), a measure of cognitive functioning (the MoCA) and a demographics questionnaire. The MoCA was administered first to minimize the potential impact of fatigue, and all other measures were administered in random order across participants. The NPI was administered to the proxy for each participant. The total length of time to administer the battery varied, ranging from 45 minutes to one and one-half hours. Proxy phone calls typically lasted about five minutes. 
Analysis of Data

Analyses were conducted with IBM SPSS Statistics Premium Grad Pack Version 21.0 (SPSS Inc., an IBM Company, Chicago, IL). AMOS version 18 (Arbuckle, 2006) was used for structural equation modeling, using the maximum likelihood method. First, the measurement model was examined (see Figure 4), then the full structural model (see Figure 3). The magnitude of standard errors and direction of variance are reported for parameter estimates. Fit indices examined include Chi-square values divided by degrees of freedom (CMIN/df; values under 3.0 were considered to be indicators of good fit), Comparative Fit Index (CFI; values of 0.95 or higher were considered indicators of good fit, and Root Mean Squared Error of Approximation (RMSEA; values under 0.05 were considered to be indicators of good fit).

\section{Preparation of Data}

Measures with $30 \%$ or more items missing were excluded from the analyses. Mean imputation substitution was used for missing data. Scatter plots were generated and examined. The data were examined for problems with collinearity, univariate outliers, and normality. None of the variables used in the model had a squared multiple correlation of 0.90 or greater, suggesting an absence of problems with collinearity. Similarly, Mahalanobis distance statistics suggested that there were no outliers in the sample. Skew and kurtosis were examined for MoCA score, GAI, NPI, CEQ, Mean situational and facial threat, positivity bias score, and peak emotion score from the Emotional Film task. The absolute values of the z-scores were all less than 3.0, and kurtosis index scores were less than 10.0, suggesting normal distribution (Kline, 2011). 


\section{Results}

Analyses are reported using alpha set at the .05 level. Age ranged from 60 to 102 years $(M=74.42, S D=11.03)$. Two who were approached were excluded from participation because of MoCA scores lower than 10. According to MoCA performance (where scores lower than or equal to 25 suggest cognitive impairment), $46 \%$ of participants' scores were suggestive of cognitive impairment. Demographic data for the total sample are presented in Table 1, as are demographic data by cognitive status (dichotomized according to MoCA scores above and below the clinical cut-off).

Several significant group differences in demographic information emerged and are displayed in Table 1. Participants below the cut-off (suggestive of cognitive impairment) were significantly older $(F(1,98)=30.11, p<.001)$, had fewer years of education $(F(1,98)=$ $20.43, p<.001)$, and more chronic health conditions $(F(1,98)=9.60, p<.01)$ than participants with scores above the clinical cut-off. Though the sample size was small, there were significantly fewer minority participants in the no-impairment group $X^{2}(1, N=100)=6.21, p<$ .05. There also were statistically significant differences in marital status between the two groups $X^{2}(1, N=100)=22.05, p<.001$. Participants with cognitive impairment were more likely to be single, divorced, or widowed, when compared to those without clinically significant levels of impairment. In turn, participants without clinically significant levels of impairment were more likely to be married or in a committed relationship, when compared to with cognitive impairment. Participants with scores suggestive of cognitive impairment were more likely to live in assisted living or nursing facilities, compared to participants who were cognitively intact $X^{2}(1, N=100)=45.59, p<.001$. There also were significant group differences according to cognitive status in the participant's relationship to his or her proxy reporter $X^{2}(1, N=90)=$ 
$41.83, p<.001$. Proxy reporters for those with clinically significant levels of impairment were more likely to be long term care facility staff members. Participants without impairment were more likely to have a spouse of partner, or another family member provide the proxy report.

The means and standard deviations for measures are reported for the total sample presented in Table 2, as are means and standard deviations according to the presence or absence of cognitive impairment as determined by performance on the MoCA. The total number of participants who completed each measure also is recorded. Measures with more than $30 \%$ of the data missing were excluded from these analyses. For those with $30 \%$ or less missing data, imputed means were used. Both age $(r=0.28, \mathrm{p}<.01)$ and MoCA scores $(r=-0.29, \mathrm{p}<.01)$, were significantly associated with missing data, suggesting that older and more impaired participants were less likely to complete all of the study measures. Participants with MoCA scores that were suggestive of cognitive impairment had significantly higher GAI scores $(F(1$, $98)=5.23, p<.05)$ and higher positive biases on the $\operatorname{AMP}(F(1,98)=4.44, p<.05)$ in comparison to those with scores suggestive of typical cognitive aging.

Internal consistency for the MoCA, GAI, CEQ, Situational Threat, and Facial Threat measures was calculated using Cronbach's alpha. The alpha statistic for the MoCA was 0.80, suggesting good internal consistency. For the CEQ total score, Cronbach's alpha was 0.86, also indicative of good internal consistency. For the Situational and Facial Threat measures, the alpha statistic was 0.89 and 0.92 , which suggests good and excellent internal consistency, respectively.

Pearson product moment correlations were used to examine convergent validity for the variables proposed as observed variables for the latent variables: Anxiety (GAI score and NPI score), Emotion Regulation (CEQ, Film peak emotion, and AMP score), and Threat (Facial and 
Situational). A medium correlation was found between the GAI and the NPI. A small, but statistically significant, correlation was observed between Facial and Situational Threat perception. Upon examination of the observed emotion regulation measures, neither Film peak emotion nor the AMP score was significantly correlated with any other variables. The CEQ, however, was weakly correlated with the measure of Facial threat, $(r=0.20, \mathrm{p}<.05)$, Situational threat $(r=0.21, \mathrm{p}<.05)$, GAI $(r=0.37, \mathrm{p}<.001)$, and NPI $(r=0.24, \mathrm{p}<.05)$. See Table 3 for a full list of correlations.

Before proceeding to the full structural model, the measurement model examining the ability of the latent variables (Emotion Regulation, Threat Perception, and Anxiety) to predict their respective indicator variables (CEQ, Film, and AMP; Facial Threat and Situational Threat; GAI and NPI scores) was examined. To ensure that the model was over-identified, error variances for Facial and Situational Threat were fixed to be equal, as were error variances for GAI and NPI and those for CEQ and Film scores. The resulting model was tested (Figure 4), and it was a good fit to the data. The Chi-square value was 9.6, with 14 degrees of freedom. The CMIN/df value was 0.69. The CFI value was 1.0 and the RMSEA value was of 0.00 . Modification indices were examined, but none of the potential modifications made conceptual sense, and thus no modifications were made. Squared multiple correlation values suggested that the latent construct, "Anxiety," accounted for $88 \%$ of the variance GAI and $31 \%$ of the variance in NPI. The construct "Threat Perception" accounted for 56\% of the variance in Facial Threat perception, $26 \%$ of the variance in Situational Threat perception. The construct "Emotion Regulation" accounted for $1 \%$ of the variance in AMP, $1 \%$ of the variance in Film scores, and $80 \%$ of the variance in CEQ. Regression weights for the model are presented in Figure 4. 
The structural model was examined next, as depicted in Figure 3. Bootstrapping was used to test for mediation, with 5000 sample iterations. The resulting model was over identified, with a Chi-Square value of 28.05 and 19 degrees of freedom. The CMIN/df value of 1.48 suggested good fit, as did the CFI value of .86 and RMSEA value of 0.07 . Modification indices were examined, though none were theoretically sound. Parameter estimates were examined. Squared multiple correlation values were examined and are presented in Figure 5. Regression weights also were examined. Of the relations between the structural variable, only the pathway between Emotion Regulation and Anxiety was significant $(b=0.41, p<.01)$. Of note, the relation between Cognitive Functioning and Anxiety was non-significant in this model $(b=-$ $0.16, p>.05)$. See Figure 5 for all of the regression weights. The direct and indirect effects of MoCA score on Emotion Regulation and Anxiety were examined for evidence of mediation. Using a 90\% bias corrected confidence interval, upper and lower bounds for the indirect effects of MoCA score on Anxiety were examined. The lower bound for indirect effects was -.16, and the upper bound was .03, suggesting the absence of a mediation effect.

Exploratory analyses were attempted to further investigate possible mediators of the relation between cognitive functioning and anxiety. Because the sample size of the current study was on the lower bound of that required for the model specified, a more sensitive test of mediation was used.

Emotion Regulation and Threat Perception were examined as potential mediators of the relation between cognitive functioning and anxiety using the Baron and Kenny (1986) method of testing for mediation. Because it is not possible to use latent variables when applying the Baron and Kenny method of testing for mediation, composite variables were computed. Pearson product moment correlations suggested that the indicator variables for Threat Perception (i.e., 
Facial and Situational Threat Ratings) and Anxiety (i.e., GAI and NPI scores) showed small to moderate, but statistically significant, correlations (See Table 3). This suggests that the indicator variables were measuring a common construct. Thus it was appropriate to compute a composite variable for these two constructs (i.e., Threat Perception and Anxiety). Composite variables were computed by converting raw scores to z-scores, then summing the z-scores of the target variables. The indicator variables for Emotion Regulation (i.e., CEQ, Film, and AMP) were not significantly correlated, suggesting that these measures may have been assessing different constructs. Thus, it was not appropriate to compute a composite variable using these measures. Because these analyses are preliminary and exploratory in nature, I examined CEQ score to represent Emotion Regulation as a potential mediator of the relation between cognitive functioning and anxiety. CEQ score was chosen because, it had the most face-validity, and it loaded most heavily onto the Emotion Regulation latent variable in the models tested.

A regression analysis examining the ability of MoCA score to predict the composite variable, Anxiety, was not significant $(\beta=-.15, t(98)=-1.51, p=.13$.$) . Because there was not a$ significant relation between the independent and dependent variables, follow up steps to examine for mediation were unnecessary. Because the relation of the Proxy reporter and his or her degree of familiarity with the participant differed across participants, another exploratory mediation analysis using the Baron and Kenny approach (1986) was attempted using only GAI score as the outcome variable, rather than the composite variable of GAI and NPI. In the first step, the MoCA score was shown to significantly predict anxiety, $\beta=-.20, t(98)=-2.02, p<.05$. In the second step, however, MoCA score did not significantly predict CEQ score, $\beta=-.0, t(98)=-$ $.09, p=.41$. Thus, no mediation effect for emotion regulation was found. 
Next, the composite variable, Threat Perception was examined as a potential mediator of the relation between cognitive functioning and GAI scores. Again, MoCA score significantly predicted anxiety, $\beta=-.20, t(98)=-2.02, p<.05$. MoCA score did not significantly predict composite Threat score, $\beta=-.03, t(98)=-.33, p=.75$. Again, no mediation effect for threat perception was found.

An exploratory hierarchical regression analysis to examine the ability of MoCA score to predict self-reported anxiety was conducted, controlling for age. When age was added in the first step of the regression, and MoCA score was added in the second step, neither variable significantly predicted self-reported anxiety..

Because some studies (e.g., Gyurak, Goodkind, Kramer, Miller, \& Levenson, 2012) suggest that executive functioning may play a key role in emotion regulation and threat perception, preliminary analyses exploring the role of executive functioning were conducted. Exploratory analyses were conducted to learn more about group differences among those with the highest and lowest levels of executive functioning. A subscale measuring executive functioning was derived from the trails, verbal fluency, and abstraction items of the MoCA. Scores ranged from zero to four. The data were divided into tertiles according to performance on the executive functioning items of the MoCA. Top and bottom tertiles were retained for analysis. In the bottom tertile, mean executive functioning subscale score was $1.24, S D=.97$. In the top tertile, mean executive functioning subscale score was $4.00, S D=.00$. Differences in performance on measures of emotion regulation, threat perception, and anxiety were examined according to executive functioning. Group differences were examined using a one-way ANOVA and are presented in Table 4. The top and bottom tertiles according to executive functioning subscale score differed significantly on MoCA total score $(F(1,71)=77.89, p<.000)$, and AMP 
performance $(F(1,71)=4.37, p<.05)$. Participants with lower executive functioning scores predictably had more overall cognitive impairment. Given that the executive functioning subscale score was derived from the MoCA total score, the MoCA score differences were expected.

Next, executive functioning was examined as a predictor of GAI score, CEQ score, and composite threat perception. Executive functioning did not significantly predict GAI, $\beta=$ $.20, t(73)=-1.74, p=.09$, nor did it predict CEQ score $\beta=-.06, t(73)=-.50, p=.62$ or composite threat $\beta=-.03, t(68)=-.23, p=.75$.

\section{Discussion}

Little is known about potential causal mechanisms that explain the relation between anxiety and cognitive impairment. This study appears to be the first to examine possible explanatory factors for this relation. The current study sampled older adults with a broad range of cognitive functioning, and tested a model that that was proposed to explain the relation between cognitive functioning and anxiety by testing emotion regulation and threat perception as potential mediating variables. The overall model showed that cognitive impairment predicted self-reported anxiety, but it failed to support the mediation hypotheses. Dichotomizing cognitive status according to the presence or absence of clinically significant levels of cognitive impairment, follow up tests of mediation were conducted to explore the relations between these variables. Exploratory analyses using both a composite variable, comprised of self and proxy reports of anxiety, and self-report of anxiety also were examined. A discussion of the results and their implications are presented below. 


\section{Differences in Anxiety, Emotion Regulation, and Threat Perception According to Cognitive}

\section{Functioning}

Before examining the results of the primary analyses, results of group differences according to cognitive status (presence or absence of cognitive impairment) are presented to better characterize the sample. Using the clinical cut-off to dichotomize the sample, initial differences in self and proxy reported anxiety, CEQ score, emotional film task, AMP, and facial and situational threat were examined. Those who were below the clinical cut-off on the MoCA (suggestive of possible cognitive impairment) were significantly older, had more physical health problems, and were more likely to reside in long-term care. Those with MoCA scores suggestive of cognitive impairment also had significantly higher scores on the GAI, supporting previous findings showing the rates of anxiety increase among older adults with cognitive impairment (e.g., Seignourel et al., 2008). The two groups also differed significantly on AMP performance. Older adults who scored below the cut-off on the MoCA were less likely to show evidence of a positivity bias in comparison to those who scored above the clinical cutoff, thus supporting the initial hypothesis.

The two groups differed significantly on the emotional film task, such that participants with cognitive impairment endorsed lower levels of emotional arousal when viewing an emotional film clip. Previous studies have shown that older adults with Alzheimer's disease have difficulty choosing labeling for emotions (Phillips, Scott, Henry, \& Bell, 2010). The PostFilm questionnaire surveyed a range of emotions, including target emotions (e.g., fear and anxiety), and non-target, but potentially salient emotions (e.g., confusion). It is possible that participants with higher levels of impairment were less adept at identifying their emotional experiences for this task, thus endorsed lower levels of arousal. 
Further, the two groups did not significantly differ on proxy reported anxiety. Proxy and self- reports of anxiety have been shown to be poorly correlated in previous studies (e.g., Gibbons et al., 2006). In the present study, this finding also could be explained, in part, by proxy choice. The degree of contact and level of familiarity likely varied according to relationship with the proxy. For example, a spouse or live-in proxy reporter may be more sensitive to signs of anxiety in the participant than a friend, an adult child who lives remotely, or a facility staff member.

Participants with cognitive impairment also did not differ according to CEQ score, in comparison to those without cognitive impairment. In line with SST, this finding could suggest that older adults prioritize emotion regulation goals, even when cognitively impaired. While this may reflect the true absence of group differences in emotion regulation, the finding also might reflect measurement problems. The CEQ has been used effectively with older adults, and it has been shown to have good internal consistency and evidence in support of convergent validity (e.g., Gould \& Edelstein, 2010; Gross et al., 1997). At the same time, it has not been used with older adults with dementia. It is possible that these measures may not be valid in an impaired population.

The absence of significant differences in facial threat perception supports Henry and colleagues' (2009) finding, which showed that healthy controls, people with MCI, and people with mild dementia performed similarly when asked to determine level of threat associated with faces. Unlike the Henry et al. 2009 study, which found the older adults with dementia were more likely to judge non-threatening situations as threatening, the current study did not find significant differences in situational threat perception between participants above and below the clinical cutoff of the MoCA. It is possible that threat perception differed appropriately according to other 
factors (e.g., physical disability or older age) that reflected true differences in potential personal level of threat.

\section{Exploratory Analyses Examining Group Differences According to Executive Functioning}

Results from analyses using a derived executive functioning subscale score, rather than total MoCA score were largely similar to analyses using global impairment scores. Those who scored in the highest and lowest tertiles according to executive functioning differed significantly on MoCA score (those in the lowest tertile scored lower overall), GAI score (those in the lowest tertile reported higher levels of anxiety), and AMP (those in the lowest tertile were less influenced by positive primer). As in the analyses using total impairment score, executive functioning subscale score did not significantly predict emotion regulation or threat perception. Executive functioning subscale score did predict anxiety, however. While the analyses were exploratory in nature, and it is worth noting that the subscale score measuring executive functioning was not empirically validated. These results suggest that the individual items that measure executive functioning and other components of cognitive functioning, may be valuable in understanding the relation between cognitive functioning and anxiety.

\section{Primary Research Results}

The primary findings outlining the model testing Emotion Regulation and Threat Perception as mediators of the relation between cognitive functioning and anxiety are discussed below. First, results of the measurement and full structural model are discussed. Then, individual pathways and follow-up analyses are discussed.

Findings from the Measurement Model. The measurement model was examined to determine the ability of the latent constructs (Anxiety, Emotion Regulation, and Threat 
Perception) to predict performance on the indicator variables (GAI and NPI; CEQ, Emotional Film, and AMP; Situation Threat \& Facial Threat ). The measurement model was a good fit to the data. In spite of the good model fit, results from the measurement model suggested possible problems with indicator variables. Specifically, only CEQ score accounted for a significant amount of variance in the latent construct, Emotion Regulation. This suggests that the other two indicator variables, the Film and AMP tasks, may have been measuring a different construct. It is possible that the method of task administration (i.e., using the computer) may have confounded performance on these two tasks. For participants with little experience with computers, the method of administration may have impacted test results.

Findings from the Structural Model. The full structural model (as shown in Figure 3) was examined, and the model was a good fit to the data. Parameter estimates were examined to address the hypothesized relations. First, those concerning emotion regulation are discussed. Contrary to expectations, cognitive functioning did not significantly predict emotion regulation skill. Because emotion regulation requires cognitive resources (e.g., Richard \& Gross, 2000), it was originally hypothesized that older adults with higher levels of cognitive impairment would have poorer emotion regulation skills. The current finding did not support this hypothesis. In line with SST (Carstensen, 2000), it is possible that the current findings reflect prioritization of maintaining one's emotional state through cognitive or behavioral emotion regulation strategies, even in the face of depleted cognitive resources. Further, SST suggests that constraints on time are associated with a shift towards emotion regulation-related goals, rather than acquisitionrelated goals (Carstensen, 2006). Shorter future time perspective may have resulted in greater prioritization of emotion regulation goals among participants with cognitive impairment, considering that those with clinically significant levels of impairment were older and had more 
chronic health problems. Thus, despite their impairments, older adults with poorer cognitive functioning may devote relatively more resources to regulating their emotions, because such goals may be prioritized. Emotion regulation also may rely on automatic processes in older adults with cognitive impairment. Goodkind and colleagues (2010) found no group differences in down-regulation following an unwarned loud noise between healthy controls and older adults with $\mathrm{AD}$ or frontotemporal dementia (FTD). When warned of the impending noise, older adults with $\mathrm{AD}$ and FTD were worse at down-regulating, when compared to healthy controls (Goodkind et al., 2010). These findings suggest that cognitive impairment may impact effortful emotion regulation, but not automatic emotion regulation. It is possible that the two emotion regulation tasks used in the current study relied on more automatic processing.

It was also hypothesized that poorer emotion regulation would predict higher levels of anxiety. While emotion regulation did significantly predict anxiety, the relation was positive, such that higher levels of emotion regulation were associated with higher levels of anxiety. This finding was unexpected. It is possible that those with higher levels of anxiety employed greater emotion regulation skills. The CEQ score, for example, is derived from self-reported ease with which the participant controls his or her emotions. It does not account for the frequency of use of emotion regulation strategies. It is possible that older adults with higher levels of anxiety are adept at emotion regulation, but have to employ emotion regulation strategies more frequently. The CEQ also may be limited in its ability to measure the true construct of emotion regulation. Researchers define emotion regulation as the process that determines type, extent, and timing of emotions a person experiences (e.g., Gross, 1998; Gross \& Thompson, 2007), and emotion regulation strategies are generally aimed at reducing negative affect. The CEQ assesses the participant's perception of self-control over the internal or external experience of certain 
emotions. First, the idea of emotional control is complex, and may have been particularly difficult for participants with cognitive impairment. Second, the measure does not assess one's ability to use strategies for emotion regulation purposes.

Findings concerning the hypothesized role of threat perception in the model were also unexpected. First, cognitive functioning did not significantly predict threat perception. While some studies have shown that cognitive impairment is associated with greater situational threat perception (Henry et al., 2009), other studies suggest that threat perception is relatively constant throughout levels of cognitive decline (e.g., Mather \& Knight, 2006). Those that found no relation between cognitive functioning and threat perception suggest that threat perception may be evolutionarily adaptive, and thus rely on automatic processing (Mather \& Knight, 2006). Similarly, threat perception and emotion regulation were not significantly correlated in the current study, again, possibly because threat perception may utilize automatic processing later in life (Mather \& Knight, 2006). Another possible explanation considers the role of emotion regulation with regard to threat perception. A study of threat perception in younger adults (Derryberry \& Reed) found that, in spite of initial anxiety-related biases towards threatening stimuli, state-anxious individuals with high levels of attentional control shifted attention to safe stimuli. This shift in attention is a type of emotion regulation strategy outlined by Gross (1998). It is possible that participants with higher levels of anxiety in the current study used emotion regulation strategies in considering the threatening stimuli, making their responses more similar to the responses of those without impairment.

Threat perception did not predict anxiety in the present model. This finding was particularly unexpected, in light of previous findings which suggest that threat perception is enhanced among people with panic disorder (Windmann \& Krueger, 1998). According to some, 
anxiety may not be associated with wholesale increased sensitivity to threat, however (Matthews, Panganiban, \& Hudlika, 2011). Rather, anxiety may be associated with subtle changes in the context of threat, relating to the costs and benefits of the potentially threatening scenario (Panganiban, \& Hudlika, 2011). Since some of the high-threat situational images likely had little relevance in the participants' lives (e.g., race-car driving, or spelunking), threat ratings may have been lower, even among those with high levels of anxiety. It is possible that targets depicting more age-relevant threatening stimuli may have been more sensitive to differences.

Finally, no evidence of mediation was observed using the full structural model. Again, measurement and methodological issues may underlie these unexpected findings. Little is known about the psychometric properties of measures of psychological factors when used in a sample of cognitively impaired older adults. Questions of reliability and respondent insight make measurement of subjective experience very difficult in this population. At the same time, objective measures, relying only on observable or proxy reported symptoms, fail to account for subjective and private experiences. There is a paucity of research concerning the assessment of psychological factors in dementia. In a critical review of the anxiety and dementia literature, Seignoural and colleagues concluded that none of the existing measures of anxiety in dementia are strong, suggesting the need for a new measure (2008). Regarding the issue of self-versusproxy report, Seignoural and colleagues recommended a measure that surveys multiple sources of data (at least person and caregiver report), to capture both observable behavioral and private symptoms of anxiety (2008). The current study also had a small N for use with Structural Equation Modeling. Though Mueller and Hancock (2010) suggested that 5 participants per parameter estimated was appropriate, others have argued that it can be difficult to detect statistically significant effects in samples under 200 (e.g., Kline, 2011). No statistically 
significant mediational effect was observed, possibly as a result of the relatively small sample size, considering the analysis used.

It also is possible that the model is simply invalid and older adults with cognitive impairment are equally effective at regulating their emotions and perceiving threat when compared to their cognitively intact peers. In spite of diminished cognitive resources, older adults with dementia may prioritize emotionally salient goals, possibly devoting more resources to emotion regulation goals. Older adults who are closer to end-of-life, and who have more chronic illnesses, may be particularly apt to devote cognitive resources to preserving emotional goals (Carstensen, 2006). If older adults with impairment either invest more effort into emotion regulation, or rely on automatic processes to maintain their emotional state, this could account for the absence of group differences.

The data were examined for potential mediation effects using the Baron and Kenny method (Baron and Kenny, 1986). These analyses were conducted because they required a smaller total number of participants to be adequately powered and, thus were more sensitive to statistically significant effects, considering the sample size of the present study. The analyses were first conducted using a composite measure of anxiety, comprised of GAI and NPI scores, as the outcome variable. Using the composite score for anxiety, level of cognitive impairment did not significantly predict anxiety. Because of potential confounds associated with proxy reporters, another regression analysis was conducted, using self-report of anxiety as the outcome variable. This analysis showed that cognitive impairment score predicted self-reported anxiety, such that poorer cognitive functioning was associated with higher levels of anxiety. The followup steps for the Baron and Kenny method showed that cognitive impairment did not significantly predict either CEQ score, or the composite threat perception. Thus neither variable was shown 
to mediate the relation. The finding that cognitive impairment predicted self-report of anxiety, but not a composite measure of proxy and self-report is interesting. This could be due, in part, to proxy differences in relationship, opportunity for observation, and insight. It also is worth considering that, while there are certainly observable signs of anxiety, it can be a private event. Other studies have shown that self-report of anxiety is poorly correlated with proxy report in a sample of older adults with Alzheimer's disease and their caregivers (Gibbons, Teri, Logsdon, \& McCurry, 2006).

The findings of the present study may have important implications for the assessment of anxiety among people with cognitive impairment. While some measures, including the GAI, have been used and tested with older adults with cognitive impairment, few were developed specifically for use with older adults with cognitive impairment (Seignourel et al., 2008). Those developed to assess anxiety in dementia include the Rating Anxiety in Dementia assessment (RAID; Shankar, Walker, Frost, \& Orrell, 1999), the Behavioral Pathology in Alzheimer's Disease Scale (BEHAVE - AD; Reisberg, Auer, \& Montiero, 1997), and the Neuropsychiatric Inventory (NPI; Cummings et al., 1994). According to Seignourel and colleagues, these measures have problematic elements. The RAID assesses anxiety over the course of one week, which may be problematic for older adults with cognitive impairment who have difficulty with recall. Both the BEHAVE - AD and the NPI survey only caregiver report, discounting the subjective report of the patient. The results of the present study suggest that self-report of anxiety is meaningful, beyond proxy report. Because of the subjective component of anxiety, it is unclear whether person and proxy report capture the same experience. 


\section{Conclusions}

The current study examined the relation between cognitive functioning and anxiety. Group differences were observed in anxiety level, such that participants with clinically significant levels of cognitive impairment endorsed higher levels of anxiety. The overall model failed to support the hypothesized relations between cognitive functioning, anxiety, emotion regulation, and threat perception using emotion regulation and threat perception as mediating variables. It is possible that the hypothesized group differences do not exist. Sample size and measurement issues also may have played a significant role in these findings. Follow-up mediational analyses using the Baron and Kenny (1986) approach showed that cognitive functioning predicted self-reported anxiety, but neither emotion regulation nor threat perception mediated the relation. Though the findings failed to support the hypotheses, the data provide some insights into these concepts and their measurement. Most notably, the findings provide support for SST, even among older adults with cognitive impairment. They also underscore the need for more research into assessment of psychological concepts for use with people who have cognitive impairment.

\section{Limitations}

The current study had several notable limitations. First, the current study is limited by the demographics of the sample. Participants were largely Caucasian/ non-Hispanic, highly educated, and female. Because the sample was not representative of the greater population, the findings may not be generalizable. According to 2010 U.S. census data, $56.9 \%$ of the people aged 65 and older are female (U.S. Census Bureau, 2011). In contrast, $68 \%$ of the current 
sample was female. Census data suggest that $72.4 \%$ of the U.S. population was white/Caucasian in 2010 (U.S. Census Bureau, 2011). The sample of the current study was $94 \%$ white/Caucasian. Methodological limitations also exist. The sample size was on the lower boundary of acceptable. The sample size may have impacted the ability to detect small effect sizes. Measurement issues also limit the current study. With the exception of the MoCA and the NPI, most measures were developed for used with younger adults or cognitively intact older adults, and it is unclear whether these measures perform similarly among older adults with cognitive impairment. The finding that cognitive functioning predicted self-reported anxiety, but not a composite variable of self and proxy reports of anxiety, also underscores the complex issues of assessment associated with cognitive impairment. Moreover, the method of presentation for some of the tasks (i.e., via computer) could have resulted in confounds. For example, participants with poor vision, slower processing speed, or lack of familiarity and comfort with computers could have performed differently on the AMP and film tasks than those without such impairments.

It is also worth noting that a screening measure was used to determine level of cognitive impairment. Though the MoCA has been shown to be sensitive and specific in detecting MCI and dementia (Nasreddine et al., 2005), it is not a diagnostic battery. Moreover, MoCA score reflects level of impairment across several domains of cognitive functioning (e.g., memory, attention, executive functioning). It is possible that impairment in certain domains (e.g., executive functioning), but not others (e.g., naming) could better explain the relation between cognitive functioning and anxiety. 


\section{Future Directions}

The present study illuminates the need for more research about anxiety and cognitive impairment. Perhaps most importantly, it underscores the need to establish valid and reliable measures of anxiety and subjective experiences for people with cognitive impairment. It also may be important to delineate the relation between self and proxy report of anxiety, both among older adults with cognitive impairment and the general population of older adults. While studies (e.g., Gibbons et al., 2006) show that self and proxy report are poorly correlated, it is unclear whether self or proxy report has more clinical utility in detecting psychopathology and monitoring treatment gains. Future studies may examine the correspondence between objective evidence of arousal (e.g., heart rate) and subjective versus objective report of anxiety symptoms in this population. Future studies also may examine emotion regulation, including its measurement, in older adults with cognitive impairment. To examine the utility of the AMP in older adults, researchers could consider varying the speeds of stimulus presentation in order to better determine account for slower processing speed with older adults.

As noted above, the present study used a gross measure of cognitive functioning in the analyses. It is possible that the relation between cognitive functioning and anxiety differs according to domain. A more fine grained analysis of cognitive functioning, examining the impact of specific deficits by domains on anxiety, emotion regulation, and threat perception, may provide new insights. A new measure of threat perception, using age-relevant threatening stimuli, also may offer insight into differences in threat perception. 


\section{References}

Airaksinen, E., Larsson, M., \& Forsell, Y. (2005). Neuropsychological functions in anxiety disorders in population-based samples: evidence of episodic memory dysfunction. Journal of Psychiatric Research, 39, 207-214.

Arbuckle, J. L. (2006). Amos (Version 17.0.2) [Computer Program]. Chicago: SPSS.

Ballard, C., Boyle, A., Bowler, C., \& Lindesay, J. (1996). Anxiety disorders in dementia sufferers. International Journal of Geriatric Psychiatry, 11, 987-990.

Ballard, C., Neill, D., O’Brien, J., McKeith, I. G., Ince, P., \& Perry, R. (2000). Anxiety, depression and psychosis in vascular dementia: Prevalence and associations. Journal of Affective Disorders, 59, 97-106.

Bannerjee, S., Smith, S. C., Lamping, D. L., Harwood, R. H., Foley, B., Smith, P., ...Knapp, M. (2006). Quality of life in dementia: More than just cognition. An analysis of associations with quality of life in dementia. Journal of Neurology, Neurosurgery, \& Psychiatry, 77, 146-148.

Barrett, L. F., Gross, J., Christensen, T. C. \& Benvenuto, M. (2001). Knowing what you're feeling and knowing what to do about it: Mapping the relation between emotion differentiation and emotion recognition. Cognition and Emotion, 15, 713-724.

Baron, R. M. \& Kenny, D. A. (1986). The moderator-mediator variable distinction in social psychological research: Conceptual, strategic, and statistical considerations. Journal of Personality and Social Psychology, 51, 1173-1182.

Beaudreau, S. A., \& O’Hara, R. (2008). Late -life anxiety and cognitive impairment: a review. American Journal of Geriatric Psychiatry, 16, 790-803. 
Beck, A.T., Epstein, N., Brown, G., \& Steer, R.A. (1988). An inventory for measuring clinical anxiety: Psychometric properties. Journal of Consulting and Clinical Psychology, 56, 893-897.

Beekman, A.T., Bremmer, M.A., Deeg, D.J., van Balkom, A.J., Smit, J.H., de Beurs, E., et al. (1998). Anxiety disorders in later life: a report from the Longitudinal Aging Study Amsterdam. International Journal of Geriatric Psychiatry, 13(10), 717-726.

Bierman, E. J. M., Comijis, H. C., Jonker, C., \& Beekman, A. T. F. (2005). Effects of anxiety versus depression on cognition in later life. American Journal of Geriatric Psychiatry, 13, 686-693.

Bierman, E. J. M., Comijis, H. C., Jonker, C., \& Beekman, A. T. F. (2007). Symptoms of anxiety and depression in the course of cognitive decline. Dementia and Geriatric Cognitive Disorders, 24, 213-219.

Blanchard-Fields, F., Stein, R., \& Watson, T. L. (2004). Age differences in emotion-regulation strategies in handling everyday problems. The Journals of Gerontology Series B: Psychological Sciences and Social Sciences, 59, P261-P269.

Boddice, G., Pachana, N. A., \& Byrne, G. J. (2008). The clinical utility of the Geriatric Anxiety Inventory in older adults with cognitive impairment. Nursing Older People, 20, 36-39.

Bradley \& Lang, (2007). The International Affective (IAPS) in the study of emotion and attention. In: J. A. Coan \& J. J. B. Allen (Eds.), The handbook of emotion elicitation and assessment (pp. 29-46). New York, NY: Oxford University Press.

Brenes, G. A., Guralnik, J. M., Williamson, J. D., Fried, L. P., Simpson, C., Simonsick, E. M., et al. (2005). The influence of anxiety on the progression of disability. Journal of the American Geriatrics Society, 53, 34-39. 
Brenes, G. A., Penninx, B. W. J. H., Judd, P. H., Rockwell, E., Sewell, D. D., \& Wetherell, J. L. (2008). Anxiety, depression, and disability across the lifespan. Aging and Mental Health, $12,158-163$.

Cameron, L. D., Booth, J. R., Schlatter, M., Ziginskas, D., \& Harman, J. E. (2006). Changes in emotion regulation and psychological adjustment following use of a group psychosocial intervention for women recently diagnosed with breast cancer. Psycho-Oncology, 16, 171-180.

Carstensen, L. (2000). Carstensen Emotion Questionnaire. Unpublished manuscript, Stanford University, Stanford, CA.

Carstensen, L. L. (2006). The influence of a sense of time on human development. Science, 312, 1913- 1915.

Carstensen, L. L. \& Mikels, J. A. (2005). At the intersection of emotion and cognition: Aging and the positivity effect. Current Directions in Psychological Science, 14, 117-121.

Carstensen, L. L., Pasupathi, M., Mayr, U., \& Nesselroade, J. R. (2000). Emotional experience in everyday life across the adult life span. Journal of Personality and Social Psychology, 79, 644-655.

Cavanagh, C. (2012). Emotion regulation strategies scale: The development and psychometric properties of a new emotion regulation measure. Unpublished manuscript, Department of Psychology, West Virginia University, Morgantown, WV.

Chemerinski, E., Petracca, G., Manes, F., Leiguarda, R., \& Starkstein, S. E. (1998). Prevalence and correlates of anxiety in Alzheimer's disease. Depression and Anxiety, 7, 166-170. 
Christensen, H., Jorm, A.F., Mackinnon, A.J., et al. (1999). Age differences in depression and anxiety symptoms: a structural equation modeling analysis of data from a general population sample. Psychological Medicine, 29, 325-339.

Clark, L. A. \& Watson, D. (1995). Constructing validity: Basic issues in objective scale development. Psychological Assessment, 7, 309-319.

Cummings, J. L. (1997). The Neuropsychiatric Inventory: Assessing psychopathology in dementia patients. Neurology, 48, S11-S16.

de Beurs, E., Beekman, A. T. F., van Balkom, A. J. L. M., Deeg, D. J. H., van Dyck, R. , \& van Tilburg, W. (1999). Consequences of anxiety in older persons: its effect on disability, well-being and use of health services. Psychological Medicine, 29, 583-593.

DeLuca, A. K., Lenze, E. J., Mulsant, B. H., Butter, M. A., Karp, J. F., Dew, M. A., ... Reynolds, C. F. (2005). Comorbid anxiety disorder in late life depression: Association with memory decline over four years. International Journal of Geriatric Psychiatry, 20, 848-854.

Derryberry, D. \& Reed, M. A. (2002). Anxiety-related attentional biases and their regulation by attentional control. Journal of Abnormal Psychology, 111, 225-236.

Fernandez-Duque, D. \& Black, S. E. (2005). Impaired recognition of negative facial emotions in patients with frontotemporal dementia. Neuropsychologia, 43, 673-687.

Ferretti, L., McCurry, S. M., Logsdon, R., Gibbons, L., \& Teri, L. (2001). Anxiety and Alzheimer's disease. Journal of Geriatric Psychiatry and Neurology, 14, 52-58.

Folstein, M. F., Folstein, S. E., \& McHugh, P., R. (1975). “Mini-mental state.” A practical method of grading the cognitive state of patients for the clinician. Journal of Psychiatric Research, 12, 189-198. 
Fox, L. S., \& Knight, B. G. (2005). The effects of anxiety on attentional processes in older adults. Aging \& Mental Health, 9, 585-593.

Fuh, J. L., Wang, S. J., \& Cummings, J. L. (2005). Neuropsychiatric profiles in patients with Alzheimer's disease and vascular dementia. Journal of Neurology, Neurosurgery, \& Psychiatry, 76, 1337-1341.

Gibbons, L. E., Teri, L., Logsdon, R. G., \& McCurry, S. M. (2006). Assessment of anxiety in dementia: An investigation into the association of different methods of measurement, Journal of Geriatric Psychiatry and Neurology, 19, 202-208.

Gill, D. J., Freshman, A., Blender, J. A., \& Ravina, B. (2008). The Montreal Cognitive Assessment as a screening tool for cognitive impairment in Parkinson's Disease. Movement Disorders, 23, 1043-1046.

Goodkind, M. S., Gyurak, A., McCarthy, M., Miller, B. L., \& Levenson, R. W. (2010). Emotion regulation deficits in frontotemporal lobar degeneration and Alzheimer's disease. Psychology and Aging, 25, 30-37.

Gould, C. E., \& Edelstein, B. A. (2010). Worry, emotion control, and anxiety control in older and young adults. Journal of Anxiety Disorders, 24, 759-766.

Gratz, K. L. \& Gunderson, J. G. (2006). Preliminary data on an acceptance-based emotion regulation group intervention for deliberate self-harm among women with borderline personality disorder. Behavior Therapy, 37, 25-35.

Gross, J.J. (1998). Antecedent- and response-focused emotion regulation: divergent consequences for experience, expression, and physiology. Journal of Personality and Social Psychology, 74(1), 224-237. 
Gross, J. J., \& Thompson, R. A. (2007). Emotion Regulation Conceptual Foundations. In J. J. Gross (Ed.), Handbook of Emotion Regulation (pp. 3-24). New York: The Guilford Press.

Gross, J. J., Carstensen, L. L., Pasupathi, M., Tsai, J., Skorpen, C. G., \& Hsu, A. Y. C. (1997). Emotion and aging: Experience, expression, and control. Psychology and Aging, 12(4), 590-599.

Gross, J. \& Levensen, R. W. (1995). Emotion elicitation using films. Cognition and Emotion, 9, 87-108.

Gruhn, D. \& Scheibe, S. (2008). Age-related differences in valence and arousal ratings of pictures from the International Affective Picture System (IAPS): Do ratings become more extreme with age?. Behavior Research Methods, 40, 512-521.

Gum, A. M., King-Kallimanis, B., \& Kohn, R. (2009). Prevalence of mood, anxiety, and substance-abuse disorders for older Americans in the National Comorbidity SurveyReplication. American Journal of Geriatric Psychiatry, 17, 769-781.

Gyurak, A., Goodkind, M. S., Kramer, J. H., Miller, B. L., \& Levenson, R. W. (2012). Executive functions and the down-regulation and up-regulation of emotion. Cognition and Emotion, $26,103-118$.

Hancock, G. A., Woods, B., Challis, D., \& Orrell, M. (2006). The needs of older people with dementia in residential care. International Journal of Geriatric Psychiatry, 21, 43-49.

Hamann, S. B., Monarch, E. S., \& Goldstein, F. C. (2000). Memory enhancement for emotional stimuli is impaired in early Alzheimer's disease. Neuropsychology, 14, 82-92.

Henry, J. D., Rendell, P. G., Scicluna, A., Jackson, M., \& Phillips, L. H. (2009). Emotion experience, expression, and regulation in Alzheimer's disease. Psychology and Aging, 24, 252-257. 
Henry, J. D., Thompson, C., Ruffman, T., Leslie, F., Withall, A., Satchdev, P., \& Brodaty, H. (2009). Threat perception in mild cognitive impairment and early dementia. Journal of Gerontology: Psychological Sciences, 64B, 603-607.

Hoe, J., Hancock, G., Livingston, G., \& Orrell, M. (2006) Quality of life of people with dementia in residential care homes. British Journal of Psychiatry, 188, 460-464.

Isaacowitz, D. M., Wadlinger, H. A., Goren, D. G., \& Wilson, H. R. (2006). Selective preference in visual fixation away from negative images in old age? An eye-tracking study. Psychology and Aging, 21, 40-48.

Jasper, F. \& Witthoft, M. (2012). Automatic evaluative processes in health anxiety and their relations to emotion regulation. Cognitive Therapy and Research, DOI: 10.1007/s10608-

\section{2-9484-1}

Jorm A. F. (2000). Does old age reduce the risk of anxiety and depression? A review of epidemiological studies across the adult life span. Psychological Medicine, 30, 11-22.

Kennedy, Q., Mather, M., \& Carstensen, L. L. (2004). The role of motivation in the age-related positivity effect in autobiographical memory. Psychological Science, 15, 208-214.

Kisley, M. A., Wood, S., \& Burrows, C. L. (2007). Looking at the sunny side of life: Age related changes in an event-related potential measure of negativity bias. Psychological Science, $18,838-843$.

Kline, R. B. (2011). Principles and practice of structural equation modeling (3rd ed.). New York, NY: Guilford Press.

Knight, M., Seymour, T. L., Gaunt, J. T., Baker, C., Nesmith, K., \& Mather, M. (2007). Aging and goal-directed emotional attention: Distraction reverses emotional biases. Emotion, 7, 705-714. 
Kryla-Lighthall, N. \& Mather, M. (2008). The role of cognitive control in older adults' emotional wellbeing. In V. Bengtson, D. Gans, N. Putney, \& M. Silverstein (Eds.), Handbook of Theories of Aging, $2^{\text {nd }}$ edition (pp. 323-344). New York, NY: Springer Publishing.

Lang, P. J., Bradley, M. M., \& Cuthbert, B. N. (1997). International affective picture system (IAPS): Instruction manual and affective ratings. Technical manual.

Lau, A. W., Edelstein, B. A., \& Larkin, K. T. (2001). Psychopathological arousal in older adults: A critical review. Clinical Psychology Review, 21, 609-631.

Lawton, M. P. (2001). Emotion in later life. Current Directions in Psychological Science, 10, $120-123$.

Lawton, M. P., Kleban, M. H., Rajagopal, D., \& Dean, J. (1992). Dimensions of affective experience in three age groups. Psychology and Aging, 7, 171-184.

Levenson, R.W., Carstensen, L.L., Friesen, W., \& Ekman, P. (1991). Emotion, physiology, and expression in old age. Psychology and Aging, 6(1), 28-35.

Lyketsos, C. G., Lopez, O., Jones, B., Fitzpatrick, A. L., Breitner, J., \& DeKosky, S. (2002). Prevalence of neuropsychiatric symptoms in dementia and mild cognitive impairment: Results from the cardiovascular health study. Journal of the American Medical Association, 288, 1475-1483.

Mather, M. (2006). Why memories may become more positive as people age. In: B. Uttl, N. Ohta, \& A. L. Siegenthaler (Eds.), Memory and emotion: Interdisciplinary perspectives (pp.135-158 ). Malden, MA: Blackwell Publishing.

Mather, M., \& Carstensen, L. L. (2005). Aging and motivated cognition: the positivity effect in attention and memory. Trends in Cognitive Sciences, 9, 496-502. 
Mather, M. \& Knight, M. R. (2005). Goal-directed memory: The role of cognitive control in older adults' emotional memory. Psychology and Aging, 20, 554-570.

Mather, M. \& Knight, M. R. (2006). Angry faces get noticed quickly: Threat detection is not impaired among older adults. Journal of Gerontology: Psychological Sciences, 61B, P54P57.

Matthews, G., Panganiban, A. R., \& Hudlika, E. (2011). Anxiety and selective attention to threat in tactical decision-making. Personality and Individual Differences, 50, 49-954.

McCurry, S. M., Gibbons, L. E., Logsdon, R. G., \& Teri, L. (2004). Anxiety and nighttime behavioral disturbances: Awakenings in patients with Alzheimer's disease. Journal of Gerontological Nursing, 30, 12-20.

McLaughlin, K. A., Mennin, D. S., \& Farach, F. J. (2007). The contributory role of worry in emotion generation and dysregulation in generalized anxiety disorder. Behaviour Research and Therapy, 45, 1735-1752.

Meyer, T. J., Miller, M. L., Metzger, R. L., Borkovec, Thomas D., et al (1990). Development and validation of the Penn State Worry Questionnaire. Behavior Research and Therapy, 28(6), 487-495.

Mobini, S. \& Grant, A. (2007). Clinical implications of attentional bias in anxiety disorders: An integrative literature review. Psychotherapy: Theory, Research, Practice, Training, 44, $450-462$.

Murphy, N. A. \& Isaacowitz, D. M. (2008). Preferences for emotional information in older and younger adults: A meta-analysis of memory and attention tasks. Psychology and Aging, 23, 263-286. 
Nasreddine, Z. A., Phillips, N. A., Bédirian, V., Charbonneau, S., Whitehead, V., Collin, I., et al. (2005). The Montreal Cognitive Assessment, MoCA: A brief screening tool for mild cognitive impairment. Journal of the American Geriatrics Society, 53, 695-699.

Olson, R. A., Chhanabhai, T., \& McKensie, M. (2008). Feasibility study of the Montreal Cognitive Assessment (MoCA) in patients with brain metastases. Support Care Cancer, $16,1273-1278$.

Orrell M. \& Bebbington, P. (1996). Psychosocial stress and anxiety in senile dementia. Journal of Affective Disorders, 39, 165-173.

Pachana, N. A., Byrne, G. J., Siddle, H., Kolosky, N., Harley, E., \& Arnold, E. (2007). Development and validation of the Geriatric Anxiety Inventory. International Psychogeriatrics, 19, 103-114.

Palmer, B.W., Jeste, D.V., \& Sheikh, J.I. (1997). Anxiety disorders in the elderly: DSM-IV and other barriers to diagnosis and treatment. Journal of Affective Disorders. 46(3), 183-190.

Payne, B. K., Cheng, C. M., Govorun, O., \& Stewart, B. D. (2005). An inkblot for attitudes: Affect misattribution as implicit measurement. Journal of Personality and Social Psychology, 89, 277-293.

Perkins, E. A. (2007). Self-and proxy reports across three populations: Older adults, persons with Alzheimer's, and persons with intellectual disabilities, Journal of Policy and Practice in Intellectual Disabilities, 4, 1-10.

Phillips, L. H., Scott, C. Henry, J. D., Mowat, D. \& Bell, J. W. (2010). Emotion perception in Alzheimer's disease and mood disorders in older adults. Psychology and Aging, 25, 3847. 
Porter, V. R., Buxton, W. G., Fairbanks, L. A., Strickland, T., O’Connor, S. M., RosenbergThompson, S., \& Cummings, J. L. (2003). Frequency and characteristics of anxiety among patients with Alzheimer's disease and related dementias. Journal of Neuropsychiatry and Clinical Neuroscience, 15, 180-186.

Reisberg, B., Auer, S. R., \& Monteiro, I. (1997). Behavior pathology in Alzheimer's disease (BEHAVE-AD) rating scale. International Psychogeriatrics, 301-308.

Ritchie, K., Artero, S., Beluche, I., Ancelin, M. N., Mann, A., Dupuy, A. M., ... Boulenger, J. P. (2004). Prevalence of DSM-IV psychiatric disorder in the French elderly population. British Journal of Psychiatry, 184, 147-152.

Rottenberg, J., Ray, R. D., \& Gross, J. J. (2007). Emotion elicitation using films. In: J. A. Coan \& J. J. B. Allen (Eds.), The handbook of emotion elicitation and assessment (pp. 9-28). London, England: Oxford University Press.

Ruffman, T., Ng, M., \& Jenkin, T. (2009). Older adults respond quickly to angry faces despite labeling difficulty. Journal of Gerontology: Psychological Sciences, 64, 171-179.

Russel, A., Bergeman, C. S., Deboeck, P., Baird, B., Montpetit, M., \& Ong, A. (2011). Emotion control during later life: The relationship between global perspectives and daily experience. Personality and Individual Differences, 50, 1084-1088.

Seignoural, P. J., Kunik, M. E., Snow, L., Wilson, N., \& Stanley, M. (2008). Anxiety in dementia: A critical review. Clinical Psychology Review, 28, 1071-1082.

Salthouse, T. (1996). Processing-speed theory of adult age differences in cognition. Psychological Review, 3, 403-428. 
Scheibe, S. \& Blanchard-Fields, F. (2009). Effects of regulating emotions on cognitive performance: What is costly for younger adults is not so costly for older adults. Psychology and Aging, 24, 217-223.

Shankar, K. K., Walker, M., \& Orrell, M. W. (1999). The development of a valid and reliable scale for rating anxiety in dementia (RAID). Aging and Mental Health, 3, 39-49.

Shapiro, A.M., Roberts, J.E., \& Beck, J.G. (1999). Differentiating symptoms of anxiety and depression in older adults: Distinct cognitive and affective profiles? Cognitive Therapy and Research, 23(1), 53-74.

Sinoff, G. \& Werner, P. (2003) Anxiety disorder and accompanying subjective memory loss in the elderly as a predictor of future cognitive decline. International Journal of Geriatric Psychiatry, 18, 951-959.

Smith, T., Gildeh, N., \& Holmes, C. (2007). The Montreal Cognitive Assessment: Validity and Utility in a Memory Clinic Setting. The Canadian Journal of Psychiatry, 52, 329-332.

Spielberger, C., Gorsuch, R. \& Lushene, R. (1983). Manual for the State-Trait Anxiety Inventory. Consulting Psychologists Press, Inc.: Palo Alto.

Teri, L., Ferretti, L. E., Gibbons, L. E., Logsdon, L. E., McCurry, S. M., Kukall, W. A., ... Larson, E. B. (1999). Anxiety in Alzheimer's disease: Prevalence and comorbidity. Journal of Gerontology, 54A, M348-M352.

Turk-Charles, S., Mather, M., \& Carstensen, L. L. (2003). Aging and emotional memory: The forgettable nature of negative images for older adults. Journal of Experimental Psychology, 132, 310-324.

Turk-Charles, S. \& Carstensen, L. L. (2008). Unpleasant situations elicit different emotional responses in younger and older adults. Psychology and Aging, 23, 495-504. 
Tweed, D., Blazer, D., \& Ciarlo, J. (1992). Psychiatric epidemiology in elderly populations. In: R.B. Wallace \& R.F. Woolson (Eds.). The epidemiologic study of the elderly (pp. 213233). New York, NY: Oxford University Press.

Urry, H. L., \& Gross, J. J. (2010). Emotion regulation in older age. Current Directions in Psychological Science, 19, 352-357.

U.S. Census Bureau. (2011). The older population:2012. Retrieved March 21, 2012, from http://www.census.gov/prod/cen2010/briefs/c2010br-09.pdf.

U.S. Census Bureau. (2011). Overview of race and Hispanic origin. Retrieved March 21, 2012, from http://www.census.gov/prod/cen2010/briefs/c2010br-02.pdf.

Wetherell, J. L., Reynolds, C. A., Gatz, M, \& Pedersen, N. L. (2002). Anxiety, cognitive, performance, and cognitive decline in normal aging. Journals of Gerontology, 57, P247$\mathrm{P} 255$.

Williams, P. G., Suchy, Y., \& Roa, H. K. (2009). Individual differences in executive functioning: Implications for stress regulation. Annals of Behavioral Medicine, 37, 126-140.

Windmann, S. \& Krueger, T. (1998). Subconscious detection of threat as reflected by an enhanced response bias. Consciousness and Cognition, 7, 603-633.

Wood, S., Cummings, J. L., Hsu, M. A., Barclay, T., Veen Wheatley, M., Yarema, K. T., \& Schnelle, J. F. (2001). The use of the Neuropsychiatric Inventory in nursing home residents: Characterization and measurement. American Journal of Geriatric Psychiatry, $8,75-83$. 
Table 1

Participant Characteristics for the Total Sample and by Cognitive Status

\begin{tabular}{|c|c|c|c|}
\hline & $\begin{array}{l}\text { Total Sample }(\mathrm{N}= \\
100)\end{array}$ & $\begin{array}{l}\text { No impairment } \\
\text { (MoCA score> 25) }\end{array}$ & $\begin{array}{l}\text { Impairment (MoCA } \\
\text { score } \leq 25)\end{array}$ \\
\hline \multicolumn{4}{|l|}{ Age } \\
\hline Mean & 74.42 & 68.60 & 79.36 \\
\hline SD & 11.03 & 7.5 & 11.19 \\
\hline \multirow[t]{2}{*}{ Range } & $60-$ & $60-$ & $61-$ \\
\hline & 102 & 89 & 102 \\
\hline \multicolumn{4}{|l|}{ Sex } \\
\hline Male (\%) & 32 & 15 & 17 \\
\hline Female (\%) & 68 & 31 & 37 \\
\hline \multicolumn{4}{|l|}{ Education (years) } \\
\hline Mean & 13.94 & 15.58 & 12.55 \\
\hline $\mathrm{SD}$ & 3.62 & 3.06 & 3.51 \\
\hline Range & $2-20$ & $9-20$ & $2-20$ \\
\hline \multicolumn{4}{|l|}{ Marital Status } \\
\hline Single $(\%)$ & 10 & 3 & 7 \\
\hline Spouse/ Committed & 46 & 32 & 14 \\
\hline \multicolumn{4}{|l|}{ Relat. (\%) } \\
\hline Separated (\%) & 1 & 1 & 0 \\
\hline Divorced (\%) & 5 & 1 & 4 \\
\hline Widowed (\%) & 38 & 9 & 29 \\
\hline \multicolumn{4}{|l|}{ Living Situation } \\
\hline Own home, no & & & \\
\hline
\end{tabular}


caregiver

Own home, w/

caregiver

ALF

Nursing Facility

Proxy Relationship

Spouse/Partner

Adult Child

Other family

LTC staff

Other

Race

Caucasian $(\%)$

African American

(\%)

Asian Pacific (\%)

Pacific Islander (\%)

Number of Chronic

Health Conditions

Mean

SD

Range 
Table 2

Means and Standard Deviations for total sample, subsample of those with MoCA scores suggestive of possible cognitive impairment, and subsample of those with MoCA scores suggestive of typical cognitive functioning and Baseline Dependent Variables

\begin{tabular}{|c|c|c|c|c|c|c|}
\hline \multirow[b]{2}{*}{ Variable } & \multicolumn{2}{|c|}{ Total Sample } & \multicolumn{2}{|c|}{$\begin{array}{c}\text { No Cognitive Impairment } \\
(\text { MoCA }>25)\end{array}$} & \multicolumn{2}{|c|}{$\begin{array}{c}\text { Cognitive } \\
\text { Impairment } \\
(\mathrm{MoCA} \leq 25)\end{array}$} \\
\hline & M & SD & M & SD & M & SD \\
\hline $\begin{array}{l}\text { MoCA** } \\
\quad(\mathrm{N}=100)\end{array}$ & 23.39 & 5.34 & 27.89 & 1.23 & 19.57 & 4.41 \\
\hline $\begin{array}{l}\text { GAI* } \\
\qquad(\mathrm{N}=100)\end{array}$ & 3.57 & 5.06 & 2.42 & 4.07 & 4.55 & 5.63 \\
\hline $\begin{array}{l}\text { NPI } \\
\qquad(\mathrm{N}=75)\end{array}$ & .96 & 2.14 & 0.66 & 1.69 & 1.21 & 2.45 \\
\hline $\begin{array}{l}\text { Situational } \\
\text { Threat } \\
\qquad(\mathrm{N}=92)\end{array}$ & 1.05 & .67 & 1.02 & .70 & 1.08 & .65 \\
\hline $\begin{array}{l}\text { Facial Threat } \\
\qquad(\mathrm{N}=94)\end{array}$ & -.98 & .88 & -.94 & .95 & -1.01 & .82 \\
\hline $\begin{array}{l}\text { CEQ } \\
\qquad(\mathrm{N}=96)\end{array}$ & 17.32 & 4.97 & 17.03 & 4.83 & 17.57 & 5.12 \\
\hline $\begin{array}{l}\text { Emotional } \\
\text { Film } \\
\qquad(\mathrm{N}=93)\end{array}$ & 5.16 & 2.44 & 5.34 & 1.94 & 5.01 & 2.48 \\
\hline $\begin{array}{l}\mathrm{AMP}^{*} \\
\qquad(\mathrm{~N}=91)\end{array}$ & .73 & .29 & .80 & .22 & .67 & .33 \\
\hline
\end{tabular}

*Subsample means significantly different at $p<.05$

**Subsample means significantly different at $p<.001$ 
Table 3

Intercorrelations for Measures of Cognitive functioning, Anxiety, Emotion Regulation, and Threat Perception

\begin{tabular}{lcccccccc}
\hline \multicolumn{1}{c}{ Measure } & 1 & 2 & 3 & 4 & 5 & 6 & 7 & 8 \\
\hline 1. MoCA & - & & & & & & & \\
2. GAI & $-.20 *$ & - & & & & & & \\
3. NPI & -.08 & $.58 * *$ & - & & & & & \\
4. CEQ & -.09 & $.39 * *$ & $.27 *$ & - & & & & \\
5. Emotional Film & .06 & .02 & -.02 & -.08 & - & & & \\
6. AMP & $.37 * *$ & -.08 & -.10 & -.07 & -.07 & - & & \\
7. Situational Threat & -.03 & $.24 *$ & -.03 & $.21 *$ & .01 & .08 & - & \\
8. Facial Threat & -.10 & .15 & -.07 & $.20^{*}$ & .04 & .02 & $.39 * *$ & - \\
\hline
\end{tabular}

$*$ Correlations are significant at $p<.05$

$* *$ Correlations are significant at $p<.001$ 
Table 4

Means and Standard Deviations for combined and individual top and bottom tertiles according to executive functioning subscale scores from the MoCA.

\begin{tabular}{|c|c|c|c|c|c|c|}
\hline \multirow[b]{2}{*}{ Variable } & \multicolumn{2}{|c|}{ Top and Bottom Tertiles } & \multicolumn{2}{|c|}{$\begin{array}{c}\text { Lowest Tertile } \\
\text { Executive functioning }\end{array}$} & \multicolumn{2}{|c|}{$\begin{array}{c}\text { Highest Tertile } \\
\text { Executive } \\
\text { Functioning }\end{array}$} \\
\hline & M & SD & M & $\mathrm{SD}$ & M & SD \\
\hline $\mathrm{MoCA}^{* *}$ & 23.39 & 5.50 & 18.48 & 5.06 & 26.56 & 2.80 \\
\hline GAI* & 3.69 & 5.50 & 5.07 & 6.71 & 2.80 & 4.40 \\
\hline NPI & 1.03 & 2.33 & 1.06 & 2.00 & 1.02 & 2.55 \\
\hline Situational & 1.10 & .66 & 1.10 & .73 & 1.10 & .62 \\
\hline \multicolumn{7}{|l|}{ Threat } \\
\hline Facial Threat & -.92 & .92 & -.79 & .95 & -1.01 & .91 \\
\hline CEQ & 17.44 & 5.29 & 17.74 & 6.56 & 17.24 & 4.35 \\
\hline $\begin{array}{l}\text { Emotional } \\
\text { Film }\end{array}$ & 5.28 & 2.23 & 5.56 & 2.40 & 5.10 & 2.12 \\
\hline AMP* & .73 & .30 & .64 & .35 & .78 & .24 \\
\hline
\end{tabular}

*Subsample means significantly different at $p<.05$

$* *$ Subsample means significantly different at $p<.00$ 


\section{Figure Captions}

Figure 1. Affective Misattribution Procedure (AMP) sample from Payne et al., 2005.

Figure 2. Example of High, Medium, and Low Threat Faces and Situations from Ruffman et al., 2006

Figure 3. Theoretical model for the relation between cognitive functioning and anxiety, with emotion regulation and threat estimation as mediators, with a proposed causal pathway leading from cognitive functioning to anxiety.

Figure 4. Measurement model with standardized estimates for the latent constructs, anxiety, emotion regulation, and threat perception.

Figure 5. Structural model with unstandardized estimates. 


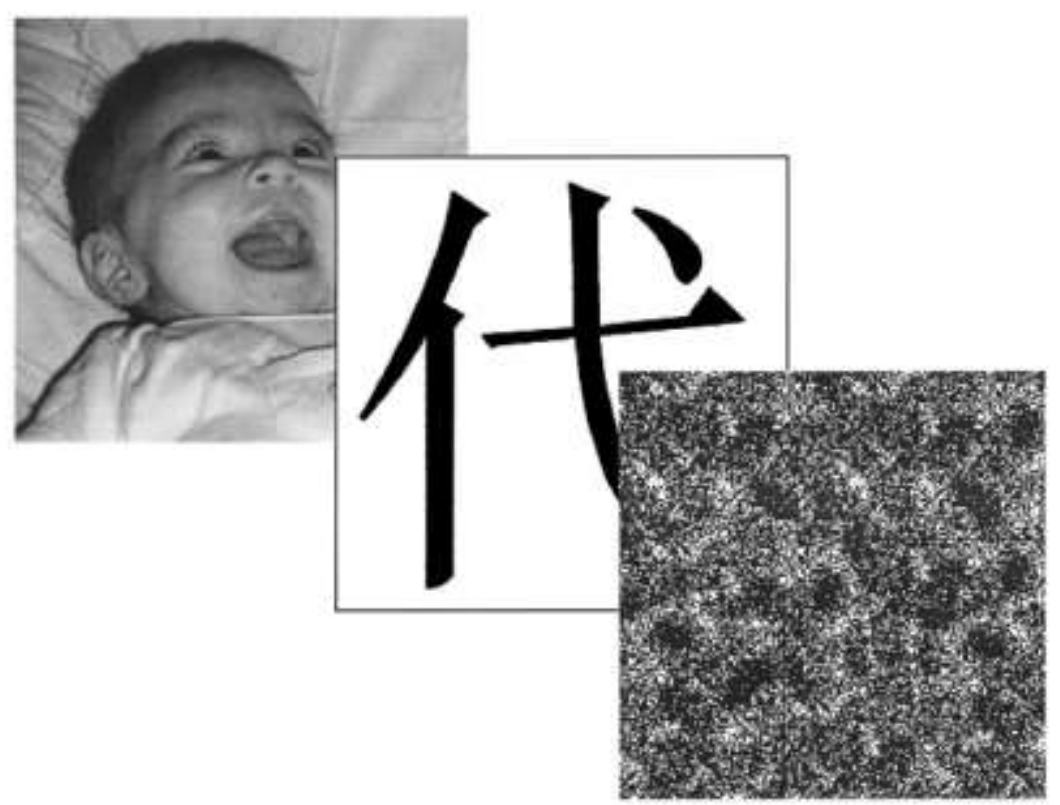



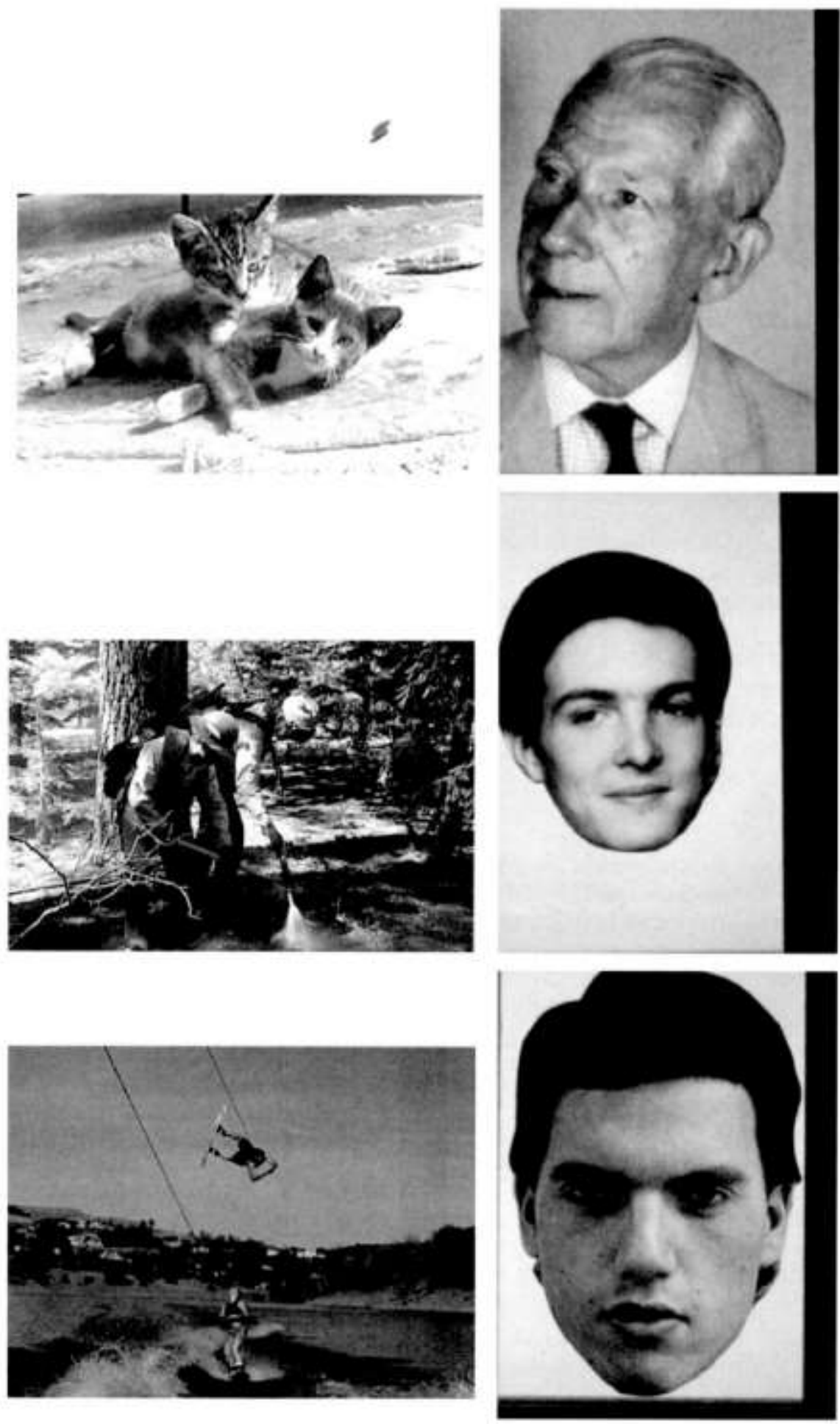


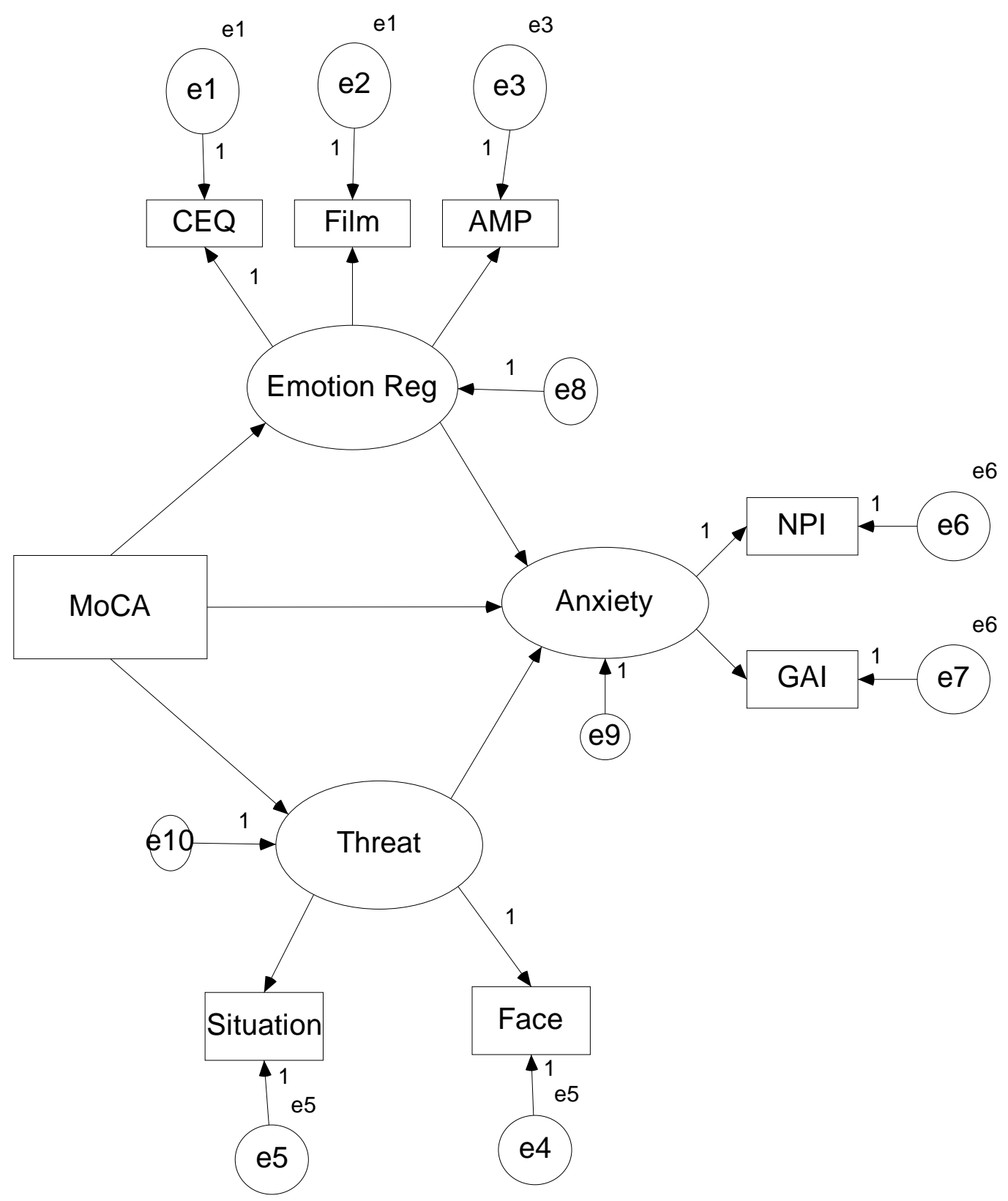









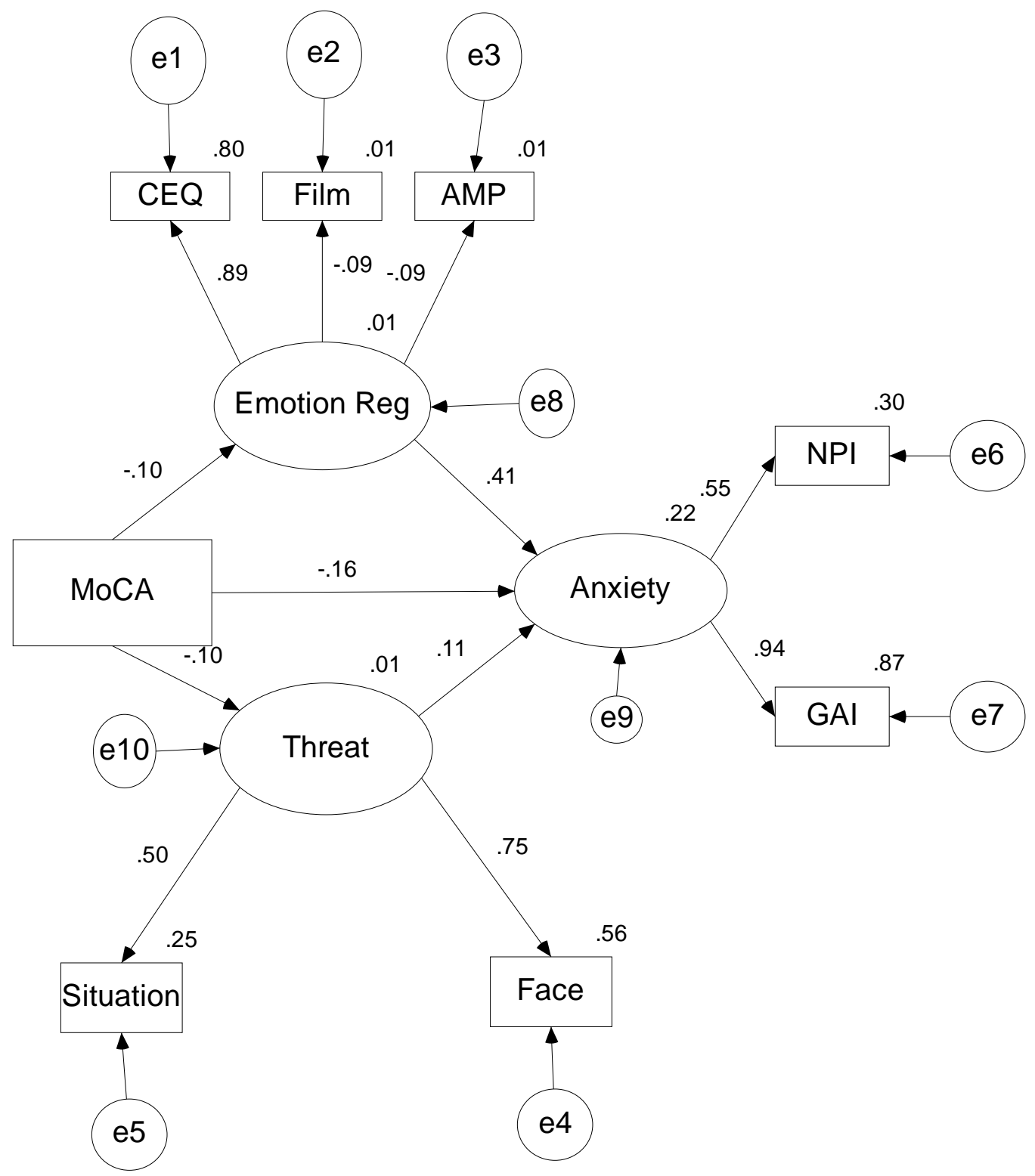


Appendix A

\section{Demographic Questionnaire}

Age: Sex: (circle one) Male

Female

Years of Education:

Marital Status: (circle one)

Single Spouse/Committed Relationship Separated Divorced Widowed

Race: (circle all that apply)

Caucasian/ White

African American/ Black

Asian American

Hispanic/ Latino

Pacific Islander

Native American (American Indian/Alaskan Native)

Current Living Arrangements: (circle one)

1. In own home/ apartment/ condominium (without a caregiver/ regular assistance)

2. In own home/ apartment/ condominium (with a caregiver/ regular assistance)

3. In another family member's (e.g., an adult child) home

4. In an assisted living facility

5. In a nursing facility

Relationship of Proxy:

1. Spouse/ Partner

2. Adult child

3. Other family member

4. Assisted living or nursing facility staff member

a. Indicate job title:

5. Other:

a. Specify:

Health Status (list chronic medical conditions): 
Appendix B

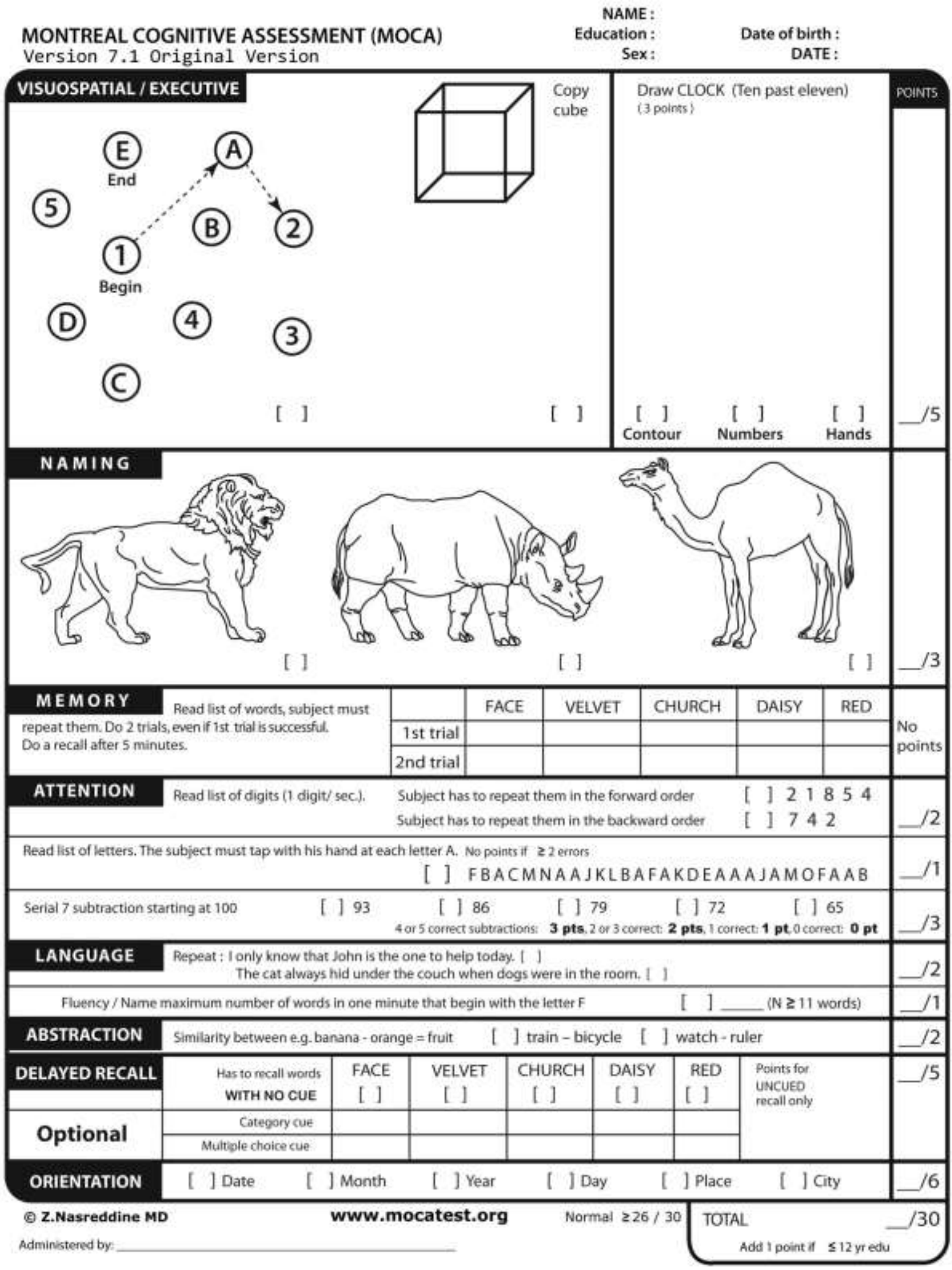




\section{Appendix C}

Geriatric Anxiety Inventory (GAI)

Agree Disagree

1. I worry a lot of the time.

2. I find it difficult to make a decision.

3. I often feel jumpy.

4. I find it hard to relax.

5. I often cannot enjoy things because of my worries.

6. Little things bother me a lot.

7. I often feel like I have butterflies in my stomach.

8. I think of myself as a worrier.

9. I can't help worrying about even trivial things.

10. I often feel nervous.

11. My own thoughts often make me anxious.

12. I get an upset stomach due to my worrying.

13. I think of myself as a nervous person.

14. I always anticipate the worst will happen.

15. I often feel shaky inside.

16. I think that my worries interfere with my life.

17. My worries often overwhelm me.

18. I sometimes feel a great knot in my stomach.

19. I miss out on things because I worry too much.

20. I often feel upset. 
Appendix D

\section{Neuropsychiatric Inventory (NPI): Anxiety Subscale}

Is the patient very nervous, worried, or frightened for no apparent reason? Does he/she seem very tense or fidgety? Is the patient afraid to be apart from you?

NO (If no, proceed to next screening question). YES (If yes, proceed to subquestions).

1. Does the patient say that he/she is worried about planned events?

2. Does the patient have periods of feeling shaky, unable to relax, or feeling excessively tense?

3. Does the patient have periods of [or complain of] shortness of breath, gasping, or sighing for no apparent reason other than nervousness?

4. Does the patient complain of butterflies in his/her stomach, or of racing or pounding of the heart in association with nervousness?

[Symptoms not explained by ill health]

5. Does the patient avoid certain places or situations that make him/her more nervous such as riding in the car, meeting with friends, or being in crowds?

6. Does the patient become nervous and upset when separated from you [or his/her caregiver]? [Does he/she cling to you to keep from being separated?]

7. Does the patient show any other signs of anxiety?

If the screening question is confirmed, determine the frequency and severity of the anxiety.

Frequency:

1. Occasionally - less than once per week.

2. Often - about once per week.

3. Frequently - several times per week but less than every day.

4. Very frequently - once or more per day.

Severity:

1. Mild - anxiety is distressing but usually responds to redirection or reassurance.

2. Moderate - anxiety is distressing, anxiety symptoms are spontaneously voiced by the patient and difficult to alleviate.

3. Marked - anxiety is very distressing and a major source of suffering for the patient.

Distress: How emotionally distressing do you find this behavior?

0 . Not at all

1. Minimally

2. Mildly

3. Moderately

4. Severely

5 . Very severely or extremely 
Appendix E

\section{Carstensen Emotion Questionnaire (CEQ)}

1. How often do you experience the following emotions?

$\begin{array}{lcccc}\text { Sadness } & \text { Often } & \text { Sometimes } & \text { Rarely } & \text { Never } \\ \text { Fear } & \mathrm{O} & \mathrm{O} & \mathrm{O} & \mathrm{O} \\ \text { Happiness } & \mathrm{O} & \mathrm{O} & \mathrm{O} & \mathrm{O} \\ \text { Anger } & \mathrm{O} & \mathrm{O} & \mathrm{O} & \mathrm{O} \\ \text { Disgust } & \mathrm{O} & \mathrm{O} & \mathrm{O} & \mathrm{O} \\ & \mathrm{O} & \mathrm{O} & \mathrm{O} & \mathrm{O}\end{array}$

2. For each of the following emotions, how well are you able to control what you feel, by that we mean the inner experience of emotions?

\section{Very well Pretty well A little Not at all}

Sadness

$\mathrm{O}$

$\mathrm{O}$

$\mathrm{O}$

$\mathrm{O}$

Fear

$\mathrm{O}$

$\mathrm{O}$

$\mathrm{O}$

$\mathrm{O}$

Happiness

$\mathrm{O}$

$\mathrm{O}$

$\mathrm{O}$

$\mathrm{O}$

Anger

$\mathrm{O}$

$\mathrm{O}$

$\mathrm{O}$

$\mathrm{O}$

Disgust

$\mathrm{O}$

$\mathrm{O}$

$\mathrm{O}$

$\mathrm{O}$

3. How well can you control the external part, that is, the signs that would let other people know what you are feeling?

Very well Pretty well A little Not at all

$\begin{array}{lcccc}\text { Sadness } & \mathrm{O} & \mathrm{O} & \mathrm{O} & \mathrm{O} \\ \text { Fear } & \mathrm{O} & \mathrm{O} & \mathrm{O} & \mathrm{O} \\ \text { Happiness } & \mathrm{O} & \mathrm{O} & \mathrm{O} & \mathrm{O} \\ \text { Anger } & \mathrm{O} & \mathrm{O} & \mathrm{O} & \mathrm{O} \\ \text { Disgust } & \mathrm{O} & \mathrm{O} & \mathrm{O} & \mathrm{O}\end{array}$




\section{Appendix F}

Post-Film Questionnaire (from Rottenberg, Ray, \& Gross, 2007)

The following questions refer to how you felt while watching the film.

\begin{tabular}{c|c|c|c|c|c|c|c|c|}
\hline 0 & 1 & 2 & 3 & 4 & 5 & 6 & 7 & 8 \\
\hline $\begin{array}{c}\text { Not at all/ } \\
\text { None }\end{array}$ & \multicolumn{1}{c|}{$\begin{array}{c}\text { Somewhat/ } \\
\text { Some }\end{array}$} \\
\end{tabular}

Please use the above scale to indicate the greatest amount of EACH emotion you experienced while watching the film

$\begin{array}{llllll}- & \text { Amusement } & - & \text { Embarrassment } & - & \text { Love } \\ - & \text { Anger } & - & \text { Fear } & - & \text { Pride } \\ - & \text { Anxiety } & - & \text { Guilt } & - & \text { Sadness } \\ - & \text { Confusion } & - & - & \text { Shame } \\ - & \text { Contempt } & - & \text { Happiness } & \text { Surprise } \\ - & \text { Disgust } & - & \text { Interest } & - & - \\ - & - & \text { Joy } & - & \end{array}$

Did you feel any other emotion during the film?

Yes

No

If so, what was the emotion?

How much of the emotion did you feel?

Please use the following pleasantness scale to rate the feelings you had during the film.

\begin{tabular}{|l|l|l|l|l|l|l|l|l|}
\hline 0 & 1 & 2 & 3 & 4 & 5 & 6 & 7 & 8 \\
\hline
\end{tabular}
unpleasant Pleasant

Had you seen this film before?

Yes

No

Did you close your eyes or look away during any scenes?

Yes No 
